\title{
EL FINAL DE LA HEGEMONÍA HISPANA EN LA COMPAÑÍA DE JESÚS: LOS MEMORIALISTAS ITALIANOS (1585-1593)*
}

\author{
POR \\ ESTHER JIMÉNEZ PABLO ${ }^{1}$ \\ Universidad de Granada
}

\section{RESUMEN:}

El episodio de los jesuitas castellanos que enviaron memoriales a la Inquisición española en contra del gobierno del General Aquaviva es uno de los más conocidos y conflictivos de la Historia de la Compañía de Jesús. Más desconocido, pero igualmente interesante, es el caso de los jesuitas memorialistas italianos que trataron de cambiar el gobierno y la espiritualidad de la Compañía, en un momento en que todavía la Orden era eminentemente hispana, con un monarca, Felipe II, que ejercía un férreo control sobre la Orden. Las quejas de estos memorialistas italianos a la Inquisición romana reflejaban un problema muy complejo, lleno de connotaciones políticas y de luchas de poder dentro y fuera de la Compañía.

PALABRAS CLAVE: memorialistas jesuitas; monarquía hispana; papado; Carlos Borromeo; Claudio Aquaviva.

\section{THE END OF THE SPAIN'S HEGEMONY OVER THE SOCIETY OF JESUS: THE ITALIAN MEMORIALISTS (1585-1593)}

\begin{abstract}
:
The episode of the Castilian Jesuits' sending of memorials (critical reports) to the Spanish Inquisition against the government of Superior General Acquaviva is one of the most famous and controversial in the history of the Society of Jesus. Less well-known but equally interesting is the case of the Italian Jesuit memorialists who attempted to alter the government and spirituality of the Society at a time when the Order was still predominantly under Spanish domination with a monarch, Philip II, who strictly controlled the Order. Complaints filed by these Italian memorialists to the Roman Inquisition reflected a very complex problem full of political intrigue and power struggles within and outside the Society.
\end{abstract}

KEY WORDS: Jesuit memorialists; Monarchy of Spain; Papacy; Carlos Borromeo; Claudio Aquaviva.

COMO CITAR ESTE ARtículo / CitATION: Jiménez Pablo, E. 2017 «El final de la hegemonía hispana en la Compañía de Jesús: los memorialistas italianos (1585-1593)». Hispania Sacra 69, 140: 619-637. doi: 10.3989/hs.2017.038

Recibido/Received 07-09-2015

Aceptado/Accepted $\quad 08-09-2015$

En la IV Congregación General en la que salió elegido general Claudio Aquaviva los ánimos de los superiores reunidos ya estaban divididos. Su elección no fue fácil y no estuvo exenta de polémicas que continuó arrastrando durante todo su mandato. En la correspondencia jesuítica

* Este artículo se inserta en los Proyectos: Maneras de vivir en la España Moderna: condiciones materiales y formas culturales de lo cotidiano. 3. Cultura, religiosidad y asistencia social. HAR2014-C3-2-P del Ministerio de Ciencia e Innovación; y La herencia de los Reales Sitios: Madrid, de Corte a Capital (Historia, Patrimonio y Turismo). Ref. H2015/HUM-3415, financiado por la Comunidad de Madrid y el Fondo Social Europeo.

1 estherjimenez@ugr.es / ORCID iD: http://orcid.org/0000-0002 $-1658-7024$ de su periodo (1581-1615) la falta de obediencia, la división jesuita en naciones o las distintas facciones jesuitas, fueron problemas que dificultaron su gobierno. A la cantidad de demandas yquejas internas en contra de la forma de gobernar de Aquaviva, se sumaba el constante control externo que ejercían los poderes políticos que, a menudo, recogían las quejas de los jesuitas molestos con Aquaviva para introducir reformas en la Compañía que favoreciesen sus intereses políticos y religiosos. En este sentido resulta paradigmático el caso de los memoriales enviados a la Inquisición española por jesuitas de las provincias castellanas, en la década de los 80 del siglo XVI, que a punto estuvieron de crear una escisión en la Orden, dado el apoyo que recibieron de los ministros 
castellanos de Felipe II. ${ }^{2}$ Entre las intenciones del monarca hispano, que defendió a los jesuitas memorialistas, estaba la de crear para la Asistencia española una figura intermedia, un comisario nacional jesuita, que actuase acorde a los intereses castellanos.

Ahora bien, en fechas parecidas, 1585-1593, desde distintos territorios italianos (especialmente desde el norte de Italia) se enviaron a la Inquisición romana un conjunto de memoriales, todos ellos anónimos, escritos por jesuitas italianos. Aunque el número de memoriales enviados era menor que en el caso de los españoles, eran suficientes como para determinar que era un grupo homogéneo de jesuitas -en ocasiones aparecen denominados como "facción»- con unos mismos intereses e ideales religiosos. Su intención era muy clara $y$, una vez analizados los memoriales, pasa por dos fases muy definidas; una primera etapa en la que se trataba de reformar el gobierno de la Compañía, concretamente se trataba de quitar a los superiores hispanos de la Orden (visitadores, rectores, provinciales) de las provincias extranjeras, y tratar de cambiar al General por uno de ellos para acelerar todos los cambios. En caso de que no saliera elegido un jesuita italiano de esta facción, al menos, se intentaría controlar al General elegido por medio de la figura de un cardenal protector que apoyase las reformas. En una segunda etapa, que iría aproximadamente de 1580 a la Congregación extraordinaria de 1593-94, sus denuncias y quejas se centraron más en la idea de reformar espiritualmente a la Compañía, aplicando en ella la denominada "reforma universal», es decir, una espiritualidad de tendencia mística proyectada para la Compañía por el cardenal Carlos Borromeo, quien dirigió a este grupo de jesuitas memorialistas desde Milán. Todas las denuncias, tanto en contra del gobierno como de la espiritualidad de la Compañía, aunque anónimas, venían firmadas colectivamente como los «deputati della Compagnia», siendo también conocidos en la documentación jesuita como los jesuitas reformadores, memorialistas, espirituales y, justo antes de la Congregación extraordinaria, como «il partito degli zelantori», afirmando así su unión como facción o grupo y destacando su celo y ardor espiritual. ${ }^{3}$

Cada memorial que fue enviado y examinado en la Congregación del Santo Oficio romano enumeraba los problemas internos de la Compañía, encontrando la solución a todos ellos en la reforma de la figura del General; si transformaban la cabeza -o mejor, si conseguían colocar en el Generalato a un jesuita reformador italiano-, se podrían hacer efectivas todas las reformas que este grupo de jesuitas planteaban. La Inquisición romana fue, por tanto, el instrumento al que los jesuitas reformadores italianos acudieron para obligar al General a acometer una serie de reformas internas -tanto de estructura como de espiritualidad- de la Compañía. En dichos memoriales se especificaba el mal que provocaba que el Generalato fuera vitalicio, la falta de conocimiento del General sobre las provincias jesuitas, la mala selección de los superiores, la falta de objetividad a la hora de dar la profesión de cuatro votos, el excesivo control del General a través de los catálogos

\footnotetext{
2 Martínez Millán 1998: 101-129; Jiménez Pablo 2014: 172-185.

3 Signorotto 1991: 190.
}

jesuitas con la descripción del humor y experiencia de cada miembro, y la falta de un cardenal protector que controlase al General como sí lo tenían el resto de órdenes religiosas. De manera que, al final, todas las quejas derivaban en un mismo mal: el General de la Compañía. No obstante, es preciso adelantar que el problema de este grupo de jesuitas italianos era algo más profundo y complejo que una aparente falta de obediencia o inconformidad con el gobierno del General, sino que el problema tenía claras connotaciones en contra de la denominada nación española, y lo que ésta representaba para el gobierno de la Compañía. El P. Benedetto Palmio, asistente de Italia, desde un principio fue el líder de esta facción de jesuitas italianos que se quejaron a la Inquisición romana. Sus quejas las plasmó en un memorial que envió al General Everardo Mercuriano (1573-1581), enumerando, uno a uno, todos los problemas que azotaban a la Compañía, y afirmando que la causa de todos los males había sido el gobierno de Laínez y Borja, los dos anteriores generales hispanos, que habían estructurado a la Compañía acorde a una mentalidad y unas estructuras eminentemente hispanas:

"Di quattro provincie italiane tre erano governate dai provinciali spagnoli et il tutto si vedeva pasar per mano di Spagnuoli. Erano soprintendenti spagnuoli, visitatori spagnuoli, secretari spagnuoli, assistenti spagnuoli» ${ }^{4}$

Se trataba de una clara advertencia de Palmio a Mercuriano, asegurándole que era el momento de cambiar la estructura de gobierno, restando influencia al gobierno de los jesuitas españoles. Continuaba Palmio preguntando:

"Che diriano, se in Spagna si mandassero Provinciali, visitatori e rettori italiani o d'altra natione? Ben disse un giorno la Santità di Nostro Signore (Gregorio XIII) che questa natione s'alzava troppo nella Compagnia. Di più, sappiamo certo che queste sono querele et lamentationi di neofiti che vogliono in ogni luogo dominare»

El P. Palmio, en su memorial, llegaba incluso a discernir entre los jesuitas hispanos dos facciones enfrentadas: la de los cristianos viejos liderada por el P. Antonio Araoz, y la de los cristianos nuevos o judeo-conversos liderada por Laínez y Borja que fue la que triunfó, y fueron estos dos generales los que introdujeron en el Compañía a los cristianos nuevos colocándoles en los puestos relevantes de la dirección de la Compañía. ${ }^{5}$ Por encima de esta distinción

4 ARSI, Institutum 106, f. 105r. El memorial de Benedetto Palmio en el apéndice de Maryks 2010: 231.

5 ARSI, Institutum 106, ff. 100v-101r. Maryks 2010: 227. Por su parte, el jesuita español Pedro de Ribadeneyra escribía otro memorial en contra del decreto de limpieza de sangre impuesto en tiempos de Aquaviva, en el que además culpaba a este grupo de jesuitas italianos liderados por Palmio de haber fomentado la implantación de los estatutos al desprestigiar a todos los jesuitas españoles por calificar a todos de ser judeo-conversos. Señalaba Ribadeneyra: "En tiempo del Padre Euerardo, ya sauemos los memoriales que se dieron al Papa contra él y su gobierno, y que los que los dieron, eran italianos, y lo que en esto se hizo y en lo que ha parado. Así que, no ay que marauillarse de lo que agora se a hecho, ni que dar non causam pro causa, pues en todo tiempo a hauido trabajo, y le han dado hombres de diferentes naciones y linages. Pero aunque fuera uerdad, no era bastante causa para hazerse nouedad en esto». MHSI, Ribadeneyra, Confessiones, Epistolae, aliaque scripta inedita: 379. Roma, 1969, II. Asimismo, Ribadeneyra señalaba que el decreto de limpieza impuesto a la Compañía en 1594, era un 
que hace y que la utiliza como excusa para desacreditar a los superiores hispanos, tachando a todos de conversos, el memorial se centra más en profundidad en un intento por remover a los jesuitas hispanos de los puestos de gobierno, y alejar a la cúpula de la orden de la influencia del monarca hispano.

En la III Congregación General, aunque la facción liderada por Palmio S.I. no consiguió que saliera elegido un General italiano de ellos, sí que consiguieron el apoyo del propio pontífice, Gregorio XIII, quien prohibió que saliera elegido un general hispano. Por tanto, es preciso tener en cuenta que esta aversión abierta a los superiores de la nación española, que aparece en diversos memoriales de los jesuitas italianos, debe ser contextualizada correctamente, dado que los cardenales y pontífices que apoyaron estos memoriales italianos desde la Inquisición, eran claramente contrarios al poderío de la Monarquía hispana, especialmente molesta en los dominios italianos.

\section{El CARDENAL CARLOS BORROMEO Y SU PROTECCIÓN A LOS JESUI- TAS MEMORIALISTAS ITALIANOS}

Este conjunto de jesuitas italianos descontentos con los superiores hispanos encontraron su mayor apoyo en el cardenal Carlos Borromeo. Sin duda ninguna, fue este cardenal quien dio cohesión y estipuló los principios de una reforma en el gobierno de la Orden, pero sobre todo, proyectó un cambio espiritual. Nepote de Pío IV (15591565), Carlos Borromeo fue uno de los cardenales más entusiastas a la hora de aplicar las reformas de la renovación católica derivada de Trento. Participó activamente en las últimas sesiones del Concilio de Trento y su obsesión por aplicar los decretos a todos los niveles, le llevó a plantearse reformas en la educación de los obispos, a ejercer un férreo control episcopal sobre el clero regular, y a marcar las devociones populares que se debían practicar. Para aplicar en la sociedad esta renovación espiritual, Borromeo tomó como modelo la congregación dirigida por Felipe Neri. Durante los años que Borromeo estuvo en la curia romana trabajó mano a mano con Neri para llegar a un método caritativo-pastoral y a una perfección espiritual que debían imitar el resto de comunidades religiosas. Tal y

agravio tan sólo a la nación española, y que siempre había habido judeoconversos en todas las instituciones, incluso conocidos cardenales eran judeo-conversos (por ejemplo el jesuita y cardenal Francisco de Toledo): De aquí se sigue la $7 \underline{a}$ razón, que esto es contra la honrra de la Compañía de España y aún de toda la nación española: la qual, o se ha de tener toda por judía y marrana, como la llaman en Italia, o por tonta y loca; por judía, si ay causa para hacer estatutos y diferencias de linajes, pues en ninguna otra nación, aun entre los que oy biuen judios y tienen sus sinagogas, ay esta diferencia. MHSI, Ribadeneyra: 380. La deshonra de ser converso en la monarquía hispana había servido ahora a los jesuitas italianos para tratar de desprestigiar a los superiores españoles y evitar sus nombramientos como superiores. Obviamente, los jesuitas italianos no pedían en sus memoriales que se impusiera la limpieza de sangre en la Compañía (esto fue una petición de las élites y los inquisidores castellanos), pero sí que contribuyeron a crear un ambiente de oposición hacia los superiores españoles. En cierto modo, el decreto de limpieza de sangre sirvió para crear una desconfianza hacia la nación española incluso para el general Aquaviva, quien debía ser muy cauto a la hora de nombrar superiores hispanos si no quería que la Inquisición española interfiriese en el gobierno de la Compañía. como analiza Cistellini en su obra detallada sobre la figura de San Filippo Neri, el humus que favoreció el desarrollo del Oratorio y que llevó a condicionar su peculiar fisonomía y su forma de actuar, fueron las profundas cicatrices que dejó el saco de Roma de 1527, que veinte años después, eran aún palpables. ${ }^{6} \mathrm{Y}$ desde luego Neri conocía bien a la Compañía de Jesús y apoyaba el cambio de gobierno de jesuitas españoles a italianos, sintiéndose orgulloso al afirmar que él había sido «el primero que metió italianos en la Compañía de Jesús». ${ }^{7}$

$Y$ ese rechazo al dominio hispano en los territorios italianos fue una de las causas que determinó a Borromeo a abandonar Roma, para dedicarse al cuidado espiritual del arzobispado de Milán, territorio de la Monarquía hispana, en 1564. No dudó en trasladar a Milán la reforma espiritual que Neri estaba aplicando en Roma, lo que provocó no pocos enfrentamientos jurisdiccionales con los distintos gobernadores españoles. Insistió en llevarse a Felipe Neri para obrar en Milán, pero la curia papal no iba a prescindir de este reformador, dado los frutos que estaba obteniendo de su actividad en Roma, siendo además uno de los confesores más requeridos por los cardenales. Ante esta negativa, Borromeo decidió centrarse en los barnabitas, que es una congregación nacida en 1533, en el mismo ambiente de recuperación después de que las tropas imperiales de Carlos $\mathrm{V}$ devastaran el norte a su paso a Roma. ${ }^{8}$ El modo que los barnabitas tenían de entender la espiritualidad y su actividad se acercaba claramente a los filipinos. En este mismo sentido hay que interpretar el interés de Borromeo por fundar otra congregación, los Oblatos de San Ambrosio, a imagen y semejanza espiritual de los filipinos de Roma. Por medio de estas congregaciones de presbíteros se fueron imponiendo en la sociedad prácticas devotas más radicales como la frecuencia de sacramentos, la oración continuada conocida como la Oración de las Cuarenta Horas, una mayor austeridad y pobreza, una actividad pastoral que se desarrolló en las calles, en los orfanatos, en las prisiones, etc. Con todo, para Borromeo era fundamental la educación de los jóvenes y para ello quiso contar con la ayuda de la Compañía, pero especificando claramente su intención de que llegaran a Milán unos jesuitas en concreto: el P. Palmio y sus compañeros, quienes fundaron los primeros colegios en Lombardía. ${ }^{9}$ Borromeo quiso que este grupo de jesuitas dirigidos por Palmio se diferenciara en su forma de actuar y de vivir la espiritualidad del común de la Orden, lo que trajo no pocos enfrentamientos con los generales Mercuriano

6 Cistellini 1989: 50-53; Pastor 1927: 184-185.

Carta del 7 de septiembre de 1595 cita en Incisa della Rocchetta y Vian 1957: 180; Ponnelle y Bordet 1986: 53.

8 Bascapè 1931; Michelini 1983.

9 En poco tiempo, Palmio ascendió a los cargos más altos de la dirección de la Compañía; de 1557 a 1559 ejerció de superintendente de los colegios de Padua y de Venecia, donde continuó predicando con asiduidad. A continuación fue nombrado Provincial de Lombardía -que incluía el gobierno de los colegios de Ferrara, Bolonia y Modena, Como y Forlì, Parma, Mondovì y Milán-, cargo que desarrolló entre los años 1559 y 1565 . Desde 1563 se instaló en Milán por deseo del cardenal Carlos Borromeo que le retuvo en su diócesis para llevar a cabo la reforma eclesiástica de Milán. Con todo, a partir de 1565 fue Asistente de Italia a lo largo de los generalatos de Borja (1565-1573) y Mercuriano (1573-1581). Marcora 1969: 9; Barbieri 1911: 231-262; Tacchi Venturi 1938: 3-5; Castellani 1934: 509-522; Dossi 1963: 308-315. 
y Aquaviva. Como las congregaciones de presbíteros en las que se apoyaba Borromeo, estos jesuitas desarrollaron un método caritativo y una espiritualidad más íntima y personal. Resultaba claro, que la provincia lombarda se convirtió en el bastión desde donde el grupo de jesuitas italianos reformadores actuaría para tratar de cambiar la situación de la Orden. El control político del Milanesado estaba en manos del monarca hispano, pero en el campo espiritual la actuación de Borromeo y estos jesuitas reformadores impedía cualquier intromisión española. Ciertamente en tiempos del General Francisco de Borja era la única provincia en la que no pudieron gobernar rectores españoles. Señalaba Scaduto en su célebre estudio que el método de gobierno de los españoles «si era fatto sentire anche nel governo di altre provincia (italianas), eccettuata la Lombarda, le cui redini non caddero in mano di gente forestiera». ${ }^{10}$

De esta manera, la dirección de los colegios de la provincia lombarda estuvo en manos de jesuitas del entorno de Borromeo. Algunos de los nombres de los superiores de la Compañía que colaboraban con Borromeo, y que gobernaron los colegios del norte de Italia, alternándose la dirección de los colegios eran, además del P. Palmio como Asistente de Italia, el P. Francesco Adorno ${ }^{11}$, primer rector del colegio de Milán (1564-1567) y (confesor de Borromeo), Leonetto Chiavone, los hermanos Gagliardi de Padua, el piamontés Giovanni Battista Velati y Fulvio Androzzi. ${ }^{12}$ También se unieron a ellos los jesuitas Giovanni Pietro Maffei, Benedetto Giustiniani, Antonio Possevino, Lorenzo Maggio, Giovanni Battista Carminata, Pietro Affonseca y Prospero Malavolta. Y precisamente algunos de estos jesuitas del entorno de Borromeo fueron los que después, en tiempos de Sixto V (1585-1590), se dedicaron a enviar memoriales a la Inquisición para cambiar la forma de gobierno de Aquaviva, ante una órgano inquisitorial receptivo a tales reformas por los cambios que introdujo dicho pontífice. El P. Chiavone, que fue gran confidente del cardenal Borromeo, gobernó los colegio de Montepulciano, Loreto, Forlì y Milán, mostrando abiertamente su hostilidad hacia los españoles al recordar, de manera despectiva, que al ingresar en la Compañía pasó «da stato d'huomo dabbene et christiano a questa Compagnia nuova trovata da giudei o marrani di Spagna», situación que estos jesuitas se propusieron cambiar. ${ }^{13}$

Cuando subió al solio pontificio Hugo Boncompagni como Gregorio XIII, en mayo de 1572, los jesuitas del entorno de Borromeo aprovecharon para tratar de convencer al pontífice -enviándole memoriales- de que era el momento idóneo para cambiar la situación de la Orden, alejándola de la influencia española. ${ }^{14}$ La elección

\footnotetext{
10 Scaduto 1972: 167.

11 Fue después provincial de Lombardía (1567-1570) y, más tarde, volvió a ejercer de provincial durante los años de 1573 a 1578. Una vez que el cardenal Carlos Borromeo elevó el colegio de Brera al grado de Universidad, eligió a Adorno para el cargo de rector durante el trienio 1581-1584. En Scaduto 1974: 522; Sommervogel 1890: 54-55; Oreste 1960: 293-295.

12 Gilmont 1961: 291-294.; Scaduto 1984: 31-54; I parraguirre 1946: 281; Tacchi Venturi 1910: 205.

13 ARSI, Ital. 116, f. 190.

14 El propio Palmio narra cómo a Gregorio XIII «non gli piaceva nella nostra religione il dominio di questa natione (la española)». ARSI, Institutum 106, f. 124r.
}

de Gregorio XIII era favorable a los jesuitas reformadores, pues este pontífice mantenía una muy buena relación con Borromeo desde hacía años. Boncompagni fue elevado a cardenal durante el pontificado de Pío IV ${ }^{15}$, cuando colaboró estrechamente en la curia papal con Carlos Borromeo y el cardenal Tolomeo Gallio (luego secretario de Gregorio XIII). ${ }^{16}$ Los tres compartían ideas parecidas en la reforma de las órdenes, queriendo devolverlas al rigor primitivo con el que fueron fundadas. El origen de estas ideas reformistas se puede rastrear cuando Borromeo instituyó en la corte romana las Notti Vaticane bajo el patrocinio de su tío Pío IV. Se trataba de reuniones nocturnas, en la habitación del propio Borromeo, que sirvieron para impulsar la renovación religiosa. En un principio, comenzaron tratando temas literarios y latinos, pero, al poco tiempo, se dieron a las cuestiones morales y teológicas, a través de las que se proponían educare lo spirito ed esercitare la virtù. ${ }^{17}$ Miembros destacados de esta academia además de Hugo Boncompagni y Tolomeo Gallio fueron también Francesco Bonomi y Francesco Alciato. ${ }^{18}$ Cuando Boncompagni salió elegido pontífice, Borromeo ya estaba en Milán, pero el cardenal ambrosiano siguió aconsejando a Gregorio XIII en materia religiosa. En el cuadro de su programa de reforma Gregorio XIII, como lo hacía Borromeo, apoyó la expansión de aquellas órdenes más activas en la sociedad católica como los barnabitas, teatinos, capuchinos y jesuitas, y reconoció canónicamente a la reforma carmelitana de Teresa de Jesús ${ }^{19}$ y a la Congregación del Oratorio de Felipe Neri (a quien estaba muy unido espiritualmente). ${ }^{20}$

Aprovechando el momento favorable que se presentaba con el pontificado de Gregorio XIII, Borromeo se empeñó en reformar a la Compañía, y para ello no cesó en intentar colocar en el generalato de la Compañía a un jesuita italiano de su entorno, en concreto, alentó a la curia papal para que durante la III Congregación (1573) no saliera elegido un general español y que durante la IV Congregación (1581) saliera elegido el P. Francesco Adorno, confesor del cardenal. Es preciso recordar que Borromeo ya había intentado antes que no saliera un general hispano, durante la II Congregación General (1565) en la que salió elegido el P. Borja, no obstante, el P. Palmio le pidió moderación al cardenal, pensando que la elección iba a ser más favorable a los intereses de Borromeo y los jesuitas de su entorno. ${ }^{21}$ Por ello, durante la III y IV Congregación

15 Pío IV le envió a Madrid para resolver el proceso de Carranza. En Serrano 1942: 76 y ss.

16 Sobre Gallio en Törne 1907.

17 Informaba Nicolás Ormaneto de la función de estas reuniones: "Sulle prime, l'accademia era stata fondata per scopo di utile ricreazione, e solo a poco a poco dalle cose per fare le dispute accademiche si trasportarono alle sacre, sebbene non allo scopo di far abbracciare la maniera di vivere ecclesiastica, giacché quella società era composta in gran parte di persone del secolo e aliene dalla vita clericale». Cita Cattaneo 1992: 10.

18 Berra 1923: 342-374.

19 Fernández Collado 1991: 245-264.

20 Cistellini 1988.

21 Así lo narra Palmio: "Havendo havuto il Papa questa informatione, commise all'Illustrissimo Cardinal Borromeo che considerasse con altri quattro cardinali ciò che si doveva fare per rimediare a questi disordini. Il cardinale Borromeo, perché amava molto la Compagnia, prima che trattasse niente di questo con altri cardinali, perché molto si fidava di me, mi communicò questo negotio et mi disse che l'animo di Sua Santità 
General fue más evidente y combativa la actuación de estos jesuitas italianos, y desde luego, triunfaron a la hora de evitar la elección de un general hispano. No es casual que, en 1573, en medio de la reunión para elegir nuevo General de la Compañía, irrumpiera el cardenal de Como, Tolomeo Gallio, como secretario del pontífice, para obligar a la Compañía, en nombre de Gregorio XIII, a que ese año no eligieran a un general hispano. Gallio había estado en Roma, y cuando Borromeo se marchó a Milán, mantuvieron una intensa correspondencia informándose de todo lo que acontecía tanto en Roma como en Milán. ${ }^{22}$ Mientras que Borromeo incitó la intromisión del pontífice en la elección a General, el P. Palmio urdió toda una trama desde dentro para evitar la elección de un nuevo general español. Esto se conoce por una relación que el P. Possevino envió al general Mercuriano en 1576. En ella, Possevino explicaba cómo una alta persona -refiriéndose a un superior italiano que era el P. Palmio, aunque ocultara su nombre- alentó a otros jesuitas italianos, incluido al P. Possevino, para que luchasen por la patria (ut pugnarem pro patria). Este superior italiano, el P. Palmio, mostraba un odio y un malestar hacia la Monarquía hispana que era conocido por todos los cardenales y grandes señores de la corte romana. ${ }^{23}$ Añadía Possevino que el mal gobierno de la Compañía era debido a las faltas de los superiores hispanos. ${ }^{24}$ El P. Palmio, como Asistente, tuvo que enfrentarse al P. Dionisio Vázquez en 1568, cuando el español era rector del Colegio Romano. ${ }^{25}$ La raíz del problema estaba en la forma en que el P. Dionisio dirigía este colegio, que Palmio tachaba de excesivo «rigor» de los españoles, alejándole del rectorado romano. Precisamente poco antes, durante la Congregación provincial romana, celebrada en mayo de 1571 , se denunció la forma de sido secretario de Borromeo cuando éste era secretario de

gobernar de los superiores españoles, y la división que provocaban entre españoles e italianos. ${ }^{26}$

Finalmente, no se pudo conseguir la elección de un italiano, por el revuelo que se produjo en las provincias españolas ante tal agravio, y el miedo a que Felipe II provocara la separación de una rama española de la Compañía. ${ }^{27}$ Con todas estas consideraciones, salió elegido el general Mercuriano, que aunque no era hispano, era de origen flamenco, vasallo, por tanto, del monarca español.

La siguiente intervención de Borromeo y los jesuitas de su entorno en las elecciones a General fue, si cabe, más directa. En 1581, fallecido el general Mercuriano, mientras se convocaba a los electores jesuitas para la IV Congregación General, en la que salió elegido el napolitano Claudio Aquaviva, Borromeo aprovechó para escribir a Gregorio XIII, advirtiéndole que no se debía dejar escapar esta ocasión que se presentaba para conseguir reformar la Compañía. En sus cartas a la curia romana, Borromeo sugería un candidato para que lo propusiera como nuevo General en la Congregación jesuita reunida. ${ }^{28} \mathrm{El}$ padre al que se refería Borromeo, que debía ser el quinto general, era el P. Francesco Adorno ${ }^{29}$, su gran confidente y director espiritual, pero si esta opción no satisfacía al pontífice, el cardenal ambrosiano proponía al P. Benedetto Palmio, líder de los jesuitas reformadores. Asimismo, Borromeo se apresuraba a informar por carta a Roma del nombre de aquellos jesuitas que, a su juicio, no debían gobernar la Orden. Entre otros, el nombre del P. Claudio Aquaviva aparecía en la carta a Gregorio XIII, pues Borromeo juzgaba que si salía elegido Aquaviva, éste no llevaría a cabo ninguna reforma en la Compañía, ni estructural ni espiritual, en parte, de nuevo, por su condición de vasallo de Felipe II, que le haría continuar en la misma estela de gobierno marcada por el también vasallo Mercuriano.

\section{LOS PRIMEROS MEMORIALES ENVIADOS A GREGORIO XIII}

La elección de Gregorio XIII dio confianza a los jesuitas del entorno de Borromeo para quejarse directamente in Roma. Et mi disse che havrebbe fatto l'offitio col Papa che havessi giudicato doversi fare per maggior servitio di Dio et magior bene della Compagnia. Cosi havendo io pensato et raccomandato questo negotio a Dio Nostro Signore, stando noi allhora congregati per fare il Generale et pensando firmamente che quello che fosse stato eletto havrebbe proveduto con il consiglio degli Assistenti che la Congregatione gi havesse dato senza pubblicar queste magagne della nostra religione, persuasi all'Illustrissimo Borromeo che facesse offitio con Sua Santità che si contentasse che la Compagnia istessa da se medesima provedesse, poiché si trovava in procinto per eleggere il nuovo Generale et per provedere a molte cose che havevano bisogno di provisione con l'autorità della Congregatione Generale. Cosi, perché io affermai all'lllustrissimo Borromeo che la Compagnia haverebbe proveduto, come io credevo di certo dovesse provedere, accettò il consiglio e parer mio, giudicando che questo fosse il meglio». ARSI, Institutum 106, f. 101r-102v. Maryks 2010: 228-229.

22 Rurale 1992: 245. Gallio fundó en Como un colegio que confió a los padres somascos, compartía con Borromeo su interés por extender a estas congregaciones de clérigos regulares por Lombardía. Pellegrini 1983.

23 García-Villoslada 1941: 144; Pavone 2004: 11; Rurale 2006: 32.

24 ARSI, Congr 20 b I-II. De rebus - Congr. Gen. I-V. Es un escrito de catorce páginas con el título «Del P. Possevino dato alla buona memoria del P. Everardo».

${ }^{25}$ En el memorial del P. Benedetto Palmio describe el suceso: "Dionisio Vasches messe il Collegio Romano in grandissima confusione (...) massime perché s'era inteso che haveva detto, che gli era stato dato il governo del Collegio Romano per domare i cervelli Italiani et per insegnarli l'obedienza». ARSI, Institutum 106, f. 114r-v, también en Maryks 2010: 241.
26 "Tutti i vecchi di questo collegio non solo fratelli ma anche padri confessano lo stato del collegio esser molto differente da quel di prima, e ciò, senz'altro testimonio, si vede per esperienza. Perché non v'è il terzo di unione e carità, che otto anni prima si vedeva, essendo ora i fratelli e fra sé disuniti e poco congiunti con i superiori; dalla quale disunione è nata l'alienazione di una nazione dall'altra, non conversando facilmente come prima, né volentieri spagnoli con italiani, non fidandosi un fratello dell'altro, molti vivendo con priori disegni. Dei superiori più volte si sono mosse querele, e perché non s'è veduto che coloro erano ugualmente amorevoli con tutti, e perché alle volte hanno fatto patire il collegio, in cose delle quali non era in collegio carestia, e perché i novizi sono quelli che da loro sono accarezzati e deputati per censori dei costumi dei collegiali e perché i novizi sono mandati innanzi, e gli si dà il governo di cose ne le quali sono veramente novizi, come è accaduto qui in collegio». En ARSI, Congr. 41, f. 12r; Sobre la situación del colegio de Roma en García-Villoslada 1954: 142-156; Fois 1995.

27 P. Astrain en su Historia de la Compañía, explica la advertencia de los superiores hispanos al pontífice de que su intromisión para que no salga elegido un español podía provocar que «los príncipes católicos quizá tomen ocasión para dividir la misma Compañía, separando a sus vasallos de la obediencia del General, sintiendo haber sido ofendida su nación por medio de exclusiones». La referencia a Felipe II en este documento resulta evidente. Astrain 1909: 13-14.

28 ARSI, De rebus Congregationis I-V. Congr. 20 b 1, f. 280v.

29 Pellegrini 1909. 
ante un papa que aparentemente les iba a favorecer. En pocos meses, estos jesuitas vieron florecer en Lombardía el instituto jesuítico. En 1572, el colegio de S. Fedele en Milán fue transferido a Brera, dejando a S. Fedele como casa profesa. En Arona se abrió el noviciado, y en Loirano el papa concedió una renta anual que permitió que este colegio hiciera frente a los gastos de manera independiente sin tener que acudir a la ayuda de Borromeo como había sucedido hasta ese momento. ${ }^{30}$ Fue por la protección de Borromeo y por la ayuda de Gregorio XIII que la Compañía pasó a ser una de las órdenes más influyentes en Lombardía.

Era, por tanto, el momento propicio para reformar la Compañía. La intención de los jesuitas reformadores italianos fue la de reunirse con Gregorio XIII para exponerle todos los problemas de la Compañía. En el año 1578 lo consiguieron, tal y como explica García-Villoslada, por medio del P. Francisco Toledo, quien consiguió una audiencia para los padres Gagliardi, Maffei, Giustiniani y Palmio. En esa misma reunión le entregaron al papa un memorial en contra de la forma de gobernar de Mercuriano. ${ }^{31} \mathrm{El} \mathrm{P}$. Toledo siempre apoyó la actuación de estos jesuitas italianos reformadores, mostrándose especialmente interesado en limitar el excesivo poder del General, y se convirtió en portavoz de estos jesuitas en la curia papal, donde era muy apreciado y tenía gran influencia sobre un elevado número de cardenales. En 1559, cuando en la Monarquía hispana de Felipe II, los ministros castellanos comenzaron a gobernar imponiendo su ideología, en la que destacaba la aplicación de los estatutos de limpieza, el P. Toledo, de ascendencia judeo-conversa, decidió marcharse a residir a Roma, donde fue bien recibido. ${ }^{32}$ Allí, el pontífice Pío V le nombró teólogo de la Sagrada Penitenciaría y predicador ordinario suyo y del colegio de cardenales. Desde Roma, se interesó por algunos puntos de las reformas que proponían el grupo liderado por el P. Palmio, pero lo que Toledo más deseaba era un mayor control del general desde la curia papal. De esta manera, de julio a diciembre de 1578, Gregorio XIII quiso atender a este grupo de jesuitas italianos que colaboraban con Borromeo, recibiendo sus memoriales y cartas que contenían las quejas en contra de la forma de gobernar del general Mercuriano..$^{33}$ El panorama descrito resultaba desolador, se explicaba la desunión y el cisma que existía en el seno de la Compañía, pidiendo al pontífice que pusiera remedio cuanto antes. Palmio culpaba al General de no querer cambiar el gobierno hispano de la Compañía y señaló algunas estrategias para limitar su poder, como una mayor descentralización del poder, o la elección de un cardenal protector que vigilase la actuación del General (probablemente pensando en Borromeo). ${ }^{34}$ Finalmente, la audiencia y los memoriales de 1578, para intentar deponer, o al menos restar poder a Mercuriano, no consiguieron el efecto esperado, porque Gregorio XIII prefirió dejar este asunto en manos del general Mercuriano, quien castigó a los jesuitas menos

30 Rurale 1995: 902.

31 En García-Villoslada 1954: 79.

32 Sobre sus datos biográficos en Santos Hernández 1998: 106-124.

33 ARSI, Roma 127, carta de Gagliardi a Mercuriano, 28 agosto 1578, ff. 103 r-104 v. Cita Catto 2009: 72.

${ }^{34}$ Se recordaba al cardenal Rodolfo Pio da Carpi quien fue protector de la Compañía ex officio, por consenso de todos a partir de 1545. Wicki 1959267. influyentes como Giustiniani, Maffei o Gagliardi, pero no pudo reprender al poderoso P. Palmio. ${ }^{35}$ No obstante, todo este asunto tuvo una fuerte repercusión en la curia papal, toda vez, que estos jesuitas contaban con la protección de diversos cardenales con quienes se reunieron y a quienes enviaron cartas quejándose del General. Según el relato de estos jesuitas, más de veinte cardenales de la curia recibieron cartas con sus críticas, mostrándose algunos de ellos muy interesados en las reformas que proponían, entre ellos destacaban cardenales que tenían vínculos con la Congregación del Santo Oficio o del Índice ${ }^{36}$, tales como Vincenzo Giustiniani (dominico, familiar del P. Giustiniani) ${ }^{37}$, Felice Peretti (franciscano, cardenal Montalto, futuro Sixto V) ${ }^{38}$, y Arcangelo de' Bianchi (dominico, cardenal de Teano)..$^{39}$

\section{HaCia una COMPAÑÍA MÍSTICA EN LOS MEMORIALES: ACHILLE GAGLIARDI S.I. Y SU REFORMA}

Cuando el grupo de jesuitas que gobernaban los colegios lombardos entraron en contacto con Borromeo,

35 Pirri 1947: 57-58; García-Villoslada 1954: 78-80.

36 Fragnito 1997: 116. Señala los siete cardenales que formaban la Congregación del Índice cuando se estableció con Pío V el 13 de septiembre de 1572: Guglielmo Sirleto, el dominico Vincenzo Giustiniani, el obispo de Bolonia Paleotti, el dominico Arcangelo de'Bianchi, el franciscano Felice Perettti di Montalto, el dominico Michele Bonelli, y el francés Niccolò Pellevé. En el siglo XVı se instituyeron la Suprema Santa Congregazione dell'Inquisizione o Santo Ufficio (1542) e Ila Congregazione dell'Indice (1571). La orden dominica fue llamada a ofrecer a la Inquisición el comisario y los «soci» (generalmente eran de la Provincia de Lombardía. Y en la Congregación del Índice eran secretarios, casi todos de la provincia romana. Penone 1998: 444.

37 Vincenzo Giustiniani, entró en la Orden de los dominicos, en la que acabó siendo general. En 1569, en misión diplomática por orden de Pío $\mathrm{V}$ acudió a la corte madrileña para tratar de solucionar algunos problemas jurisdiccionales con Felipe II producidos en las Iglesias de Milán y Nápoles. En Madrid, defendió la actuación de Carlos Borromeo en Milán. Por esta misión, que no obtuvo los resultados esperados para Roma sobre el Milán y Nápoles, Pío V le concedió en 1570 el cardenalato. Entre sus actuaciones más destacadas, estuvo presente en las últimas sesiones del concilio de Trento, por su mediación se introdujeron los teatinos en Génova. Una vez hecho cardenal, participó en las congregaciones del Índice y de obispos y regulares. En Catalano 1954-1955: 26, 58, 79 y ss., 125, 138; Busolini 2001.

38 Felice Peretti Moltalto, futuro Sixto V (1585-1590), ingresó en el monasterio franciscano de Montalto, llegando a ser vicario general de los Franciscanos en 1566. En 1570 fue nombrado cardenal, dedicándose en un primero momento al estudio y divulgación de las obras de San Ambrosio por encargo de Pío V. Para la búsqueda de los manuscritos, Peretti echó mano de Carlos Borromeo quien le proporcionó la documentación necesaria. Asimismo, Pío $\mathrm{V}$ le introduce en la Congregación de los obispos y regulares y en el Congregación para el proceso de Carranza. Y en 1571 participa en la Congregación del Índice. Durante su pontificado se asiste a una mayor centralización del papado a través de quince congregaciones estables, siendo la más importante la del Santo Oficio, para el mantenimiento de la fe y la pureza espiritual. Junto a él, estuvo el P. Francisco Toledo, al que admiraba como predicador pontificio. Costa 1986; Parisciani 1991; Delumeau 1961; Giordano 2000.

39 Arcangelo de'Bianchi (1516-1580) nació en Gambolo, Pavía. En su juventud entró en el monasterio dominico de Vigevano. De joven, acompañó en varias misiones a su superior, Fray Michele Ghislieri, futuro Pio V, quien durante su pontificado le nombró en 1566 obispo de Teano, y cuatro años más tarde, le concedió el cardenalato. Entre sus actividades en la curia, estuvo siempre vinculado a la Inquisición romana (fue nombrado comisario general del Santo Oficio en 1565-1566), y a la Congregación del Índice de la que fue prefecto durante el pontificado de Gregorio XIII. 
comenzaron a reclamar para la Compañía una espiritualidad más contemplativa, al mismo tiempo que llevaban a cabo unas prácticas religiosas impropias de la Compañía, con una oración mucho más personal e íntima, claramente alejada de la oración "práctica» que imponían Mercuriano y Aquaviva al común de la Orden. ${ }^{40}$ No es de extrañar esta búsqueda de una mayor perfección espiritual si servían a los intereses del prelado ambrosiano, al que como avisaba el provincial de Milán, Giovanni Battista Peruschi, no le gustaba ni «el modo ni el espíritu de la Compañía». ${ }^{41}$

La obsesión de Borromeo era la búsqueda de una perfección espiritual, propia de oratorianos o barnabitas ${ }^{42}$, que trasladó al grupo de jesuitas que colaboraban con él y que quiso hacerla extensible a toda la Orden sin el apoyo de los Generales de la Orden. La relación de Borromeo con los Generales de la Compañía llevaba tiempo en conflicto. El caso del predicador jesuita Giulio Mazzarino quien criticó el excesivo poder de Borromeo, ridiculizando su ritualidad y radicalidad religiosa en el arzobispado en el año 1579, le llevó a enfrentarse a Mercuriano y Aquaviva por no castigar severamente al jesuita, en el peor momento de las disputas jurisdiccionales entre el gobernador español de Milán y el arzobispo. ${ }^{43} \mathrm{En}$ ese mismo año, Borromeo escribía a monseñor Speciani, su agente en Roma, sobre sus ganas de reformar la Compañía, dado que Mercuriano seguía la forma de gobernar de los generales españoles: "Quanto a quello che voi mi scrivete intorno a questa Compagnia son già molti anni che io la vedo stare in pericolo grande, se non si pone efficace rimedio". Por eso continuaba Borromeo en su carta a Speciani:

"Quanto a quel che mi dite, che venendo io costi potrei portare qualche utile alla riforma di questa Compagnia, io credo che non potrei essere in ciò di giovamento alcuno, perché mi tengono per sospetto in quella causa del padre Giulio; et cosi direbbero molto di più quando io mettessi mano alle cose che gli premono tanto; però bisognerebbe che vi mettessero altri la mano». ${ }^{44}$

La tensión entre el General y Borromeo continuó, incluso peor, en tiempos de Aquaviva, así como siguieron

\footnotetext{
40 Iparraguirre 1964: 148.

41 "ll maggior travaglio è con il cardinale, il quale non intende né gusta il modo et spirito della Compagnia, et noi non bastiamo ad intendere il suo modo et spirito et perciò ci dà molto da fare. Li nostri nelli pareri et consigli et cose che occorrono a trattar seco e con suoi sudditi clerici et laici vanno al solito fondati sopra la dottrina come dei Dottori et con equità et soavità al modo ch'usa la Compagnia, et lui che non vuol ma seguita una certa idea di perfettione che si è formato nell'intelletto a suo modo, et vuol per forza tirarci tutti dentro, non approva il nostro modo et gli pare che siamo larghi et che buttiamo per terra la disciplina ecclesiastica et con quello zelo si disgusta ogni di più del fatto nostro, di modo che si serve poco dei nostri teologi et manco che può s'impaccia con noi, parendogli che siamo contrarii a'suoi desideri, dai quali non basta nessuno col suo consiglio a ritirarlo». ARSI, Ital. 153, ff. 181r-183v.

42 El P. Guibert, en su estudio sobre la espiritualidad jesuítica señalaba que uno de estos jesuitas reformadores, el P. Androzzi, con sus escritos sobre la recepción más frecuente de la Eucaristía, se alejaba de las disposiciones de los Generales jesuitas, reacios a tan «exagerado» postulado, para ponerse en armonía con otras sociedades de sacerdotes italianas que defendían del mismo modo la frecuencia del sacramento a diario. Tales "sociedades de sacerdotes», continuaba Guibert, eran los barnabitas de Milán y los oratorianos de Roma. Guibert 1953: 200, 262, 371-372.

43 Rurale 1992: 217 y ss.; Rurale 1997.

44 Cita Rurale 1992: 245
}

los problemas entre el cardenal y los gobernadores españoles. ${ }^{45}$

La obra pastoral de Borromeo en Milán había propiciado un ambiente religioso radical, haciendo de esta sede arzobispal el centro de todas las aspiraciones de reforma espiritual de la Compañía. ${ }^{46} Y$ en este ambiente reformador, los gobernadores españoles no podían intervenir, ante la amenaza de ser excomulgados. ${ }^{47}$ Por su parte, los jesuitas del entorno de Borromeo se habían convertido en críticos de la política del monarca hispano en Milán, utilizando la dirección espiritual de mujeres devotas como medio de ataque al gobierno español. Se trataba de mujeres místicas que, en muchos casos, experimentaban revelaciones, profecías y visiones. Éstas eran protegidas por el cardenal ambrosiano, quien favorecía el intercambio espiritual entre la Compañía y estas mujeres místicas, a pesar de los intentos frustrados, primero de Mercuriano y luego de Aquaviva, por poner freno a estas desviaciones espirituales. A menudo, estas mujeres predecían el futuro, que era interpretado por los jesuitas milaneses, y en ocasiones las predicciones estaban relacionadas con cuestiones políticas. ${ }^{48}$ Fue el caso del P. Giovanni Battista Peruschi quien confesaba a una mujer milanesa a la que la divinidad le revelaba los castigos que recibiría Felipe II por el mal gobierno de Milán. ${ }^{49}$ En este caso, se trataba de profecías sobre el futuro del monarca hispano, predicciones sobre la muerte de su hijo Carlos, y sobre el excesivo crédito que el monarca mostraba a ciertos ministros, así como revelaciones sobre el castigo que le llegaría al monarca por sus ansias de dominio. ${ }^{50}$

Dentro de este ambiente de reforma religiosa, que escondía un profundo resentimiento al dominio español, destacó el P. Achille Gagliardi. De la mano de este jesuita, y de su dirigida, la dama milanesa Isabella Berinzaga, se precipitó en Milán la renovación espiritual de la Compañía. ${ }^{51}$ Este movimiento de reforma espiritual dirigido por Gagliardi, apoyado por un nutrido número de jesuitas italianos, no debe desvincularse del movimiento de reforma del P. Palmio y de sus críticas al gobierno de los superiores españoles, de hecho, Gagliardi fue uno de los jesuitas que envió memoriales a Gregorio XIII. Ahora bien, con Gagliardi en Milán, en la década de los 80 del siglo XVI, la reforma toma matices más espirituales, acorde a la reforma que proponía Borromeo. La biografía de Gagliardi revela que siempre se interesó por una espiritualidad más contemplativa, distinta de la impuesta por los generales. Cuando vivió en Roma, frecuentó la congregación de Felipe Neri, siendo invitado por sus dotes como predicador, donde asimiló prácticas de la espiritualidad filipina. ${ }^{52}$ Gagliardi entró en la Compañía junto con sus hermanos, Leonetto y Ludovico, y con su

45 Guerra 2001: 88

46 Marcocchi 1995: 845-893.

47 Giannini 1998 y Borromeo 1998.

48 Sobre la confesión de jesuitas a místicas en Prosperi 1996.

49 El P. Peruschi nació en Roma en el año 1525. Desde joven frecuentaba a los espirituales de Felipe Neri, pero decidió entrar en la Compañía en 1555. Entre sus cargos más relevantes fue rector en Florencia, dirigió el seminario romano y, más tarde, fue nombrado provincial de Milán. Scaduto 1968: 114.

50 Lo narraba todo por carta el P. Sebastiano Morales a Mercuriano. Milán, 25 marzo 1579, ARSI, Hist. Soc. 164, ff. 16r-17r.

51 Viller 1931.

52 Cistellini 1989. 
amigo Antonio Possevino cuando escucharon predicar al P. Benedetto Palmio en Padua. ${ }^{53}$ Desde joven se interesó por el crecimiento espiritual y la oración, aplicando el esquema de las tres vías: purgativa, iluminativa y unitiva. Asimismo participó en la revisión de la Ratio Studiorum de la Compañía, exigiendo un mayor celo a la hora de practicar los ejercicios espirituales. ${ }^{54}$ Desde Milán, Carlos Borromeo reclamó la presencia de Gagliardi para dirigir el colegio de Brera en 1572, no obstante, su ida se retrasó hasta 1580. Tres años más tarde, fue nombrado prefecto de la casa de San Fedele, y fue desde entonces que la espiritualidad de Gagliardi conectó con la de su penitente, la joven milanesa.

Dentro de los casos de jesuitas dirigiendo la espiritualidad de mujeres místicas, el caso de Gagliardi y Berinzaga resultaba más complejo, pues escondía matices reformadores, que seguían las directrices borromaicas. Además de Gagliardi, existía un grupo de jesuitas que fomentaban el misticismo de esta joven, que venía unido a brotes de profetismo y visiones. ${ }^{55}$ Jesuitas como Francesco Vipera, Gregorio Mastrilli, Giovanni Mellini, Giuseppe Biondo, Ludovico Mansone, apoyaban la mística de esta mujer. ${ }^{56}$ Ahora bien, esta dama milanesa además de recibir por inspiración divina el perfeccionamiento espiritual y probar métodos de oración más afectiva con Gagliardi, también recibía -igualmente por inspiración divina- consejos sobre cómo reformar la espiritualidad y el gobierno de la Compañía, criticando así, de manera indirecta, la mala gestión de Aquaviva. Era evidente que el P. Gagliardi estaba utilizando el misticismo exagerado ${ }^{57}$ de la joven para llevar a cabo el movimiento de reforma espiritual de la Compañía. Enterado Aquaviva de las intenciones de los jesuitas milaneses, poco pudo intervenir el General, ante unos jesuitas que en Milán estaban protegidos por el cardenal Carlos Borromeo, quien además conocía a la joven mística y a su familia, fomentando la espiritualidad

53 MHSI, Lainii Monumenta V: 391, 399 y 411. Madrid: 1915; Ibídem VI: 714 y 727. Madrid: 1915; Castellani 1945: 114-119.

54 Aicardo 1922: 435-436; Tacchi Venturi 1951: 339 y ss.

55 No resulta extraño que la Compañía se encargara de la dirección espiritual de mujeres contemplativas o místicas, y que acabe produciéndose una conexión espiritual entre confesor y penitente. Lo interesante es que, en 1579, Mercuriano envía a Milán a Sebastián Morales como visitador para controlar las manifestaciones exacerbadas de piedad de los jesuitas de San Fedele, emitiendo un juicio favorable a estos vínculos espirituales entre confesores jesuitas y devotas. Ahora bien, por esos mismos años, Mercuriano cortaba en la Monarquía Hispana cualquier relación de los jesuitas con las monjas carmelitas descalzas por el temor a levantar sospechas ante la Inquisición española.

56 Catto 2009: 91-92. Precisamente el provincial de Milán, Giuseppe Biondo, informaba en un principio del círculo espiritual de Milán, años más tarde, Aquaviva le alejaba del cargo por los rumores que señalaban a Biondo como colaborador de Berinzaga: «alcuni che parevano spirituali, che non erano molti, davano fácilmente in spiriti peregrini et modi d'orare alieni dalla vocatione nostra et pericolosi d'illusioni, in sottrars dall'operare con i prossimi, in rendersi molto difficili ad accomodarsi al nostro modo di procederé et lasciarsi aplicar a quello che fosse giudicato maggior servitio di Dio. Altri poi, che perso il promo fervore erano divenuti inquieti et amatori di una certa libertà, sotto specie di soavità et spirito d'amore, come proposito dal nostro Instituto, venivano facilmente a stimare ogni essattezza, severità, scrupolo et l'osservanza di regole, cose da novitii, con li quali et con tutti quelli che il tutto regolavano all'humana prudenza et alla politica et ai dissegni s'accomodavano allo spirito et viver religioso di nostra vocatione, non si trovava modo di tenerli a segno, né vero rimedio alla radice del loro male».

57 Petrocchi 1948: 21, 53 y 1954. que esta dama profesaba. ${ }^{58}$ La situación cambió en $1584 .{ }^{59}$ cuando el cardenal Borromeo falleció, y Gagliardi comenzó a ser atacado desde la curia jesuítica. Aquaviva va a tratar de controlar, por un lado, a todos aquellos jesuitas que apoyan las reformas de Gagliardi-Berinzaga, y para ello envió a un visitador ${ }^{60}$, y por el otro, va a exigir que sean examinados los escritos del P. Gagliardi, de manera un poco silenciada, tratando de evitar que este asunto llegara a manos de la Inquisición romana. ${ }^{61}$ La principal obra que se examinó en Roma fue el Breve compendio intorno alla perfezione cristiana, que recogía las experiencias místicas y revelaciones de Isabella, junto con reflexiones espirituales de Gagliardi, y sus anhelos de reforma. ${ }^{62}$ Gagliardi se vio obligado a realizar una serie de modificaciones sobre este texto que vio su aprobación el 22 de octubre de $1592^{63}$, siendo examinado por un teólogo jesuita, el P. Francisco de Toledo, protector de los jesuitas reformadores. ${ }^{64}$ Resultó, por tanto, un duro golpe para el general Aquaviva al comprobar que Gagliardi tenía fuertes apoyos en Roma. Finalmente, el Breve Compendio se publicó primero en Francia, a partir de 1596, donde fue llevado por el P. Pierre Coton (después predicador en la corte de Enrique IV de Francia), gozando de gran aceptación en la escuela espiritual que se dio entorno a Bèrrule, madame d'Acarie, Ollier y Lallemant, siendo después readaptado a la mística francesa bajo el título Abrégé de la perfection $^{65}$, y luego, más tarde, a partir del año 1611, fue publicado en Brescia. El reconocimiento y carisma del que Gagliardi gozó en Milán, complicaba el control que Aquaviva quería ejercer sobre su persona. Para tratar de evitar, o al menos reducir, los encuentros entre Gagliardi y Berinzaga, el general Aquaviva envió varias instrucciones ${ }^{66}$, pero la inminente celebración de una congregación extraordinaria, que tendría lugar entre 1593 y 1594, volvió a encender los ánimos de los memorialistas italianos. El «partito degli zelatori» (los que actúan con gran celo), era como se hacían llamar, y Gagliardi era su líder espiritual. Su intención era la de imponer a toda la Compañía el florecimiento místico que

58 Biblioteca Ambrosiana, F. 38 inf. 170, 190.

59 Viller 1931.

60 El P. Lorenzo Maggio fue enviado como visitador en 1588, acabando su misión sin emitir un juicio claro sobre la dama y su experiencia mística, enviando los documentos y escritos de Gagliardi a Roma.

61 La mujer no podia "essere mezzo et istrumento di riformar religioni, essendovi da Dio, quando bisogna, altri mezzi ordinati a questo fine». Carta de Aquaviva a Vipera, 16 de septiembre de 1595, ARSI, Ital. 71, f. 91r.; Aquaviva creó en el Colegio Romano un filtro -nombrando un grupo de jesuitas superiores- que sirvió para prevenir cualquier intromisión de la Congregación inquisitorial o del Índice en la producción literaria jesuita. Sobre la Inquisición y las mujeres devotas en Italia: Malena 2003: 293-296. Advierte que El breve Compendio no fue prohibido hasta el siglo XVIII; Clement 1998: 185.

62 Breve compendio di quanto siè raccolto intorno all'eminentissima perfectione christiana alla quale ogniuno della Compagnia debe procurare d'arrivare conforme al suo santo instituto o Breve compendio di quanto si è raccolto intorno all'eminentissima perfettione, a che og'uno della Compagnia deve procurare di arrivare. Pirri 1951: 238.

63 Pirri 1951: 237.

64 Malena 2003: 295.

65 Dagens 1931: 348; Luca 1931 y Dagens 1952: 190.

66 "Quanto all'andar in casa di Madonna Isabella, non conviene andar per gl'estremi, e sarebbe inconvenientissimo quell'ordine ch'ella scrive, che nessuno (vi) metta piede: anzi conviene che si consoli quella serva di Dio et non si dia nota con tale ritiramento». ARSI, Med. 21, f. 17r. Carta del General al P. Achille Gagliardi, 2 de septiembre de 1589. 
se estaba produciendo en Milán ${ }^{67}$, proyectando una reforma religiosa tal y como se había realizado en la mayoría de las grandes familias religiosas ${ }^{68}$, y para ello pedían a Gagliardi que hiciera circular entre ellos -en ese momento unos sesenta jesuitas con anhelos de reforma- todas sus obras espirituales, equiparando la importancia de sus escritos a los ejercicios espirituales de Ignacio de Loyola. ${ }^{69}$ Señalaba Gagliardi a Aquaviva que:

"conviene che et di dentro si dia molto all'oratione et allo spirito et faccia dar anco molta oratione sopra il negotio; et di fuori, dadovero, quanto è possibile, mostri ex corde di voler farlo (...) in far buoni superiori et sopra tutto applicarsi alle cose spirituali, con aiutarli in questa materia quanto è possibile». ${ }^{70}$ Dando más tiempo a la oración y contemplación. ${ }^{71}$

En la Congregación extraordinaria de 1593-94 confluyeron tantos intereses -los de los memorialistas españoles, de los italianos, los de la Inquisición española, los de Felipe II, los de los pontífices- que la Compañía se hubiera dividido si no hubiera sido por el interés de Clemente VIII en que la Compañía siguiera unida. Si algo tenía claro este pontífice es que la reforma debía partir del papado no de partidos internos en el seno de la Orden. La Compañía, por tanto, debía servir a los intereses de Roma y tras la Congregación se data el mayor número de instrucciones enviadas por Aquaviva para los provinciales para transformar la espiritualidad, las misiones y la educación, que sirvió para adaptar los intereses de la Orden a los del papado. ${ }^{72}$ Ciertamente, la reforma espiritual del P. Gagliardi no se llevaría a cabo, como se analizará más adelante, pero la presión que ejerció este grupo de jesuitas desde Gregorio XIII, produjo cambios evidentes en la Compañía, como evitar el nombramiento de un general español, o la transformación en los colegios -aunque lenta y con mucho cuidado de no crear malestar en la monarquía hispana- comenzando a relevar a los superiores hispanos en el gobierno de las provincias extranjeras ${ }^{73}$, o

67 Signorotto 1991: 190. El 2 de noviembre de 1593, justo un día antes de celebrar la Congregación extraordinaria, Gagliardi escribía a su hermano explicando que Isabella Berinzaga tenía las claves para reformar la Compañía porque esta mujer conocía bien el funcionamiento de la Orden. Catto 2009: 103.

68 «Poter attendere allo spirito secondo I'Istituto puro, et non impediti come erano hora, allegando molte difficoltà et molti occorrent secondo lo stato di presente; et che così molti seguitariano come in altre religioni, anzi quasi in tutte si è fatto». ARSI, Ital.161, ff. 194r-195r. Milán, 6 julio 1594.

69 "Secretamente, fra noi soli, con tener noi tutti i volumi al modo delli essercitii del padre Ignatio». En ARSI, Med. 21, Epp. Gen. 1576 1583, f. 198.

70 ARSI, Ital. 161, f. 198 v, carta del 5 de octubre 1594 de Gagliardi a Aquaviva.

71 Guerra 2002

72 A golpe de instrucción adaptó a la Compañía a los intereses de Roma. En 1599, el General se empeñaba en impulsar las misiones y extender así los principios del catolicismo romano con su guía De modo instituendarum missionum. De ese mismo año era el reglamento definitivo de la Ratio Studiorum que reorganizó la educación de los colegios jesuitas, y también mandó De usu orationis et poenitentiae, en un intento por ajustar el difícil equilibrio entre dedicar tiempo a la oración y la praxis de las actividades apostólicas. En 1600, envió su obra Industriae ad curandos animae morbos, con la que trataba de exaltar el papel de superiores y la obediencia a éstos, para el funcionamiento correcto de la Compañía; Quondam 2004.

73 Jiménez Pablo 2010. la imposición de la Ratio Studiorum como nuevo método didáctico, en el marco de una escolástica renovada. El apoyo de los memorialistas italianos a la elaboración de este nuevo plan de estudios perseguía acabar, de una vez por todas, con el vigente método «español» de enseñanza en todos los colegios, aunque ellos hubieran preferido que en la Ratio hubiera habido todavía una mayor cobertura a las cuestiones espirituales. ${ }^{74}$

\section{LA RECEPCIÓN DE LOS MEMORIALES EN LA INQUISICIÓN ROMANA (1585-1593)}

Durante el pontificado de Sixto V (1585-1590) se data el envío de memoriales con un goteo constante por parte de los jesuitas reformadores italianos a la Congregación inquisitorial. No resulta casual que acudiesen en este momento a la Inquisición, pues con Sixto $\mathrm{V}$ aparecía un aparato prácticamente renovado, más compacto $y$ centralizado ${ }^{75}$, que además de velar por las cuestiones de fe, sirvió también, en relación a las órdenes religiosas, para imponer una ideología religiosa reformada. ${ }^{76} \mathrm{Y}$ en este ambiente favorable a la renovación, los jesuitas italianos debían tratar de conseguir la de la Compañía, enviando memoriales a la Inquisición, para que los inquisidores dieran por ortodoxas sus reformas, especialmente ante un pontífice que cuando era cardenal se había mostrado favorable a una mayor intervención papal en el gobierno de los Generales. ${ }^{77}$ La intensa actividad inquisitorial vivida durante el pontificado de Sixto $\mathrm{V}^{78}$ seguía las mismas directrices -de control e intransigencia- que había marcado antes Paulo IV, quien utilizó a la Inquisición para apartar tanto a aquellos cardenales que se quería excluir de la elección papal, como a aquellos cardenales con más

74 Sobre el proceso de elaboración de la Ratio en Soto Artuñedo 1999; Zanardi 1998; Anselmi 1981.

75 Col y Paolin 1991: 23-24.

76 Es un papa interesado en la reforma de las órdenes, en tratar de recuperar la pureza de fe y el rigor con el que fueron fundadas. Le interesan sobre todo aquellas órdenes más activas en la sociedad. Así, el 18 de marzo de 1586, aprobaba la Orden de los Camilos, cuyo fundador Camilo de Lelis había sido discípulo de Neri. El 5 de mayo de 1586 aprobaba a los Foglianti o Feuillants, una reforma cisterciense de gran austeridad y pobreza, permitiendo que se extendieran fuera de la frontera francesa, siendo bien recibidos en los territorios italianos por donde se extendieron. El 1 de octubre de 1586 reconoce como orden religiosa a la Orden Hospitalaria de San Juan de Dios (conocidos como fatebenefratelli). El 19 de abril de 1587 fueron aprobados los agustinos descalzos. El 10 de julio de 1587 se erigió en Congregación la provincia de Carmelitas descalzos que había sido fundada por la madre Teresa de Jesús. El 1 de julio de 1588 fueron aprobados los Clérigos Regulares Menores o Caracciolini. En 1588 favoreció la elección para los Teatinos de un preposito general vitalicio con residencia en Roma. Asimismo aprobó a los Conventuales Reformados el 15 de octubre de 1587, que se establecieron en territorio italiano tras haber sido suprimidos en la monarquía hispana en 1562. Promovió también la reforma de los Franciscanos Descalzos llevada a cabo por Giovanni Battista Lucarelli de Pesaro, su antiguo alumno.

77 Peretti había sido uno de los veinte cardenales que habían recibido cartas de los memorialistas italianos durante el pontificado de Gregorio XIII.

78 En 1533 entró en los franciscanos conventuales. Años más tarde, en 1557, Paulo IV le nombró inquisidor para la República de Venecia. En 1560 el cardenal Michele Ghislieri, futuro Pío V, le quiso en Roma como consultor de la Congregación de la Inquisición y más tarde, ya como pontífice, le hizo cardenal en 1570. 
influencia y poder en el colegio cardenalicio. Los procesos inquisitoriales contra los cardenales Morone o Pole ${ }^{79}$, vinculados a corrientes erasmistas y valdesianas, rebelaban esta lucha de poder en la que triunfó la facción que apoyaba a Giampietro Carafa, saliendo elegido pontífice con el nombre de Paulo IV, imponiendo, a partir de entonces, una rígida intransigencia religiosa. ${ }^{80}$ De hecho, como señala Prosperi en su estudio, la Inquisición estuvo monopolizada durante toda la segunda mitad del siglo XVI por cardenales como Michele Ghislieri (dominico, futuro Pío V) ${ }^{81}$ y Felice Peretti (franciscano, futuro Sixto V), de orígenes humildes que habían llegado a ser cardenales, y que entendían que tanto la renovación católica como la búsqueda de una mayor pureza de la fe, pasaban obligatoriamente por un mayor control inquisitorial. ${ }^{82}$ El triunfo de Carafa, con sus estrechos colaboradores Ghislieri y Peretti, y el control que éstos tres prelados ejercieron sobre la Inquisición romana durante la II mitad del s. XVI, significó además un impetuoso control inquisitorial sobre las órdenes religiosas. ${ }^{83}$ Se trataba de reformar, vía inquisitorial, a las comunidades religiosas devolviéndolas a su pureza doctrinal originaria. ${ }^{84}$ Con Carafa, Ghislieri y Peretti, dominicos y franciscanos monopolizaron el aparato inquisitorial romano ${ }^{85}$, convirtiéndose en ejemplares inquisidores, que les sirvió para ascender a obispados y, más aún, para ser nombrados cardenales, y llegar algún día, como en el caso de Ghislieri y Peretti, a ser elegidos pontífices. ${ }^{86}$ Ciertamente, cuando Peretti era inquisidor general en Venecia actuó siempre con gran intransigencia. ${ }^{87} \mathrm{Y}$ una vez elegido pontífice bajo el nombre de Sixto V, en 1585, dio más poder, si cabe, a la Inquisición. En esta centralización, el cardenal Giulio Antonio Santori se convirtió en el artífice y mano ejecutora que reforzó el poder del aparato inquisitorial. ${ }^{88}$ Con Sixto V y Santori se confirmaron todos los privilegios que tenía el Santo Oficio, se reconoció la costumbre del papa de presidir las reuniones de la Congregación, y se definieron y aumentaron las materias de fe que eran consideradas herejía. ${ }^{89}$ En definitiva, colocó a la congregación del Santo Oficio por encima del resto de congregaciones cardenalicias, reconociendo en ella, por un lado, el control supremo de la fe, y por el otro, el uso de un instrumento privilegiado del poder centralizador del pontífice. ${ }^{90}$ Con respecto a la Compañía, Sixto $V$ mostró la misma desconfianza que Paulo IV y Pío $\mathrm{V}$ a la actividad de aquellos jesuitas españoles que seguían gobernando los

79 Firpo y Marcatto 1981: 71-142; Firpo 1981: 59 y ss.; Firpo 1983.

80 Bethencourt 1997: 146-147.

${ }^{81}$ Sobre la actividad inquisitorial bajo el pontificado de Pío V en Col 2006: 424-441.

82 Prosperi 1991: 49.

83 Romeo 2002: 15.

84 Sobre la intransigencia inquisitorial en tiempos de Paulo IV en Borromeo 2003: 328-329.

85 Col 2003: 351.

86 Prosperi 1996: 137-138.

87 Col 2006: 366-368; Paschini 1926: 314-320.

88 La elección el 7 de enero de 1565 de Ghislieri como Pío V, quien seguía la estela de Paulo IV, abría a Santoro las puertas de su ascenso en la curia. Lo nombró enseguida consultor y cardinal de Santa Severina (mayo 1570). Ricci 2002.

89 Prosperi 1996: 141

90 La Congregación inquisitorial era colocada en el primer puesto por medio del documento Immensa aeterni Dei (22 enero 1588). Borromeo 2003: 323-327. colegios del territorio italiano. ${ }^{91}$ Siempre miró con recelo los privilegios de la Orden, especialmente los que afectaban a la Inquisición, como era el hecho de que la Compañía estuviera exenta de la jurisdicción ordinaria de la Inquisición. Con este privilegio, los confesores jesuitas representaban una amenaza para la Iglesia católica, porque muchos penitentes, con una simple confesión a un jesuita, quedaban absueltos, incluso de casos de herejía. El 1 de octubre de 1587, Sixto $\checkmark$ promulgó una orden por la que quedaba prohibido a los jesuitas absolver de herejía en confesiones y obligaba a que estos casos fueran reenviados al tribunal inquisitorial. ${ }^{92}$

Sixto $\mathrm{V}$ estuvo interesado en diversas ocasiones en reformar el gobierno de la Compañía, y más aún cuando le llegaban memoriales con quejas a la Inquisición romana. Tradicionalmente se ha pensado que los memorialistas castellanos, favorecidos por la Inquisición española, influyeron en la decisión del papa Peretti de examinar los documentos del gobierno de la Compañía, pero no se ha atendido de igual forma, a la influencia que los memorialistas italianos ejercieron sobre la decisión de Sixto $\mathrm{V}$ de que las Constituciones de la Compañía pasaran por la revisión de la Inquisición romana.

Aprovechando estas ganas de reformar la Compañía que Sixto $\mathrm{V}$ manifestó -mostrándose especialmente combativo a partir de 1588, cuando los memorialistas españoles e italianos estaban en pleno ataque al gobierno de Aquaviva, no obstante, con intereses distintos- llegaba a manos de los inquisidores romanos uno de los memoriales italianos que mejor se conocen. El 31 de mayo de 1589, los inquisidores se interesaban por este documento que enunciaba, uno a uno, los errores del gobierno de la Compañía. ${ }^{93}$ Dicho memorial fue leído ante la Congregación inquisitorial reunida el 18 de febrero de 1590, presidida por el papa Peretti. ${ }^{94}$ En él, el anónimo jesuita se quejaba de la mala selección de los superiores, del abuso de los catálogos provinciales para dichas elecciones, de la negatividad del general a visitar las provincias jesuitas, de los errores cometidos por los generales españoles, etc. ${ }^{95}$ Empeoraba la situación el cargo vitalicio del General, con un despotismo en sus decisiones cuya solución, podría ser, la nómina de un cardenal protector. En el conjunto de soluciones que se daban, resultaba llamativa

91 El caso del P. Bobadilla era evidente. Bobadilla fue enviado en 1562 a la costa de Calabria donde debía ocuparse de convertir a los herejes de la comunidad valdense. Bobadilla se interesó allí por aquellos herejes arrepentidos, usando un método poco intransigente que no gustó nada a Ghislieri. Parente 1992: 31; Sin embargo, años antes, en 1541, Bobadilla predicaba, confesaba y había propuesto lecturas devotas en la corte del cardenal Pole en Viterbo, donde fue bien acogido y consiguiendo grandes frutos, tal y como se relata en una carta del cardenal Pole del 22 de diciembre de 1541. ARSI, Epp. Ext. 7, I, 3.

92 «Sixto V», en O’Neill y Domínguez 2001: 2976-2978.

93 Se refiere a él Guerra 2001: 110-116.

94 Archivo de la Congregación para la Doctrina de la Fe (ACDF), Santo Offizio, St.St. N3g, Varie relative a gesuiti, II governo della Compagnia per natura e conditione sua è molto difficile e pericoloso, ff. 347-360v. La copia se conserva en ARSI, Fondo Gesuitico 700, Miscellanea 1, ff. 194r-212v. Cfr. Guerra 2001: 114.

95 "Li spagnoli, che fin'all'hora tenevano ancora il dominio pensavano di continuare nel Generalato avanzando in numero tutte le altre voci, fecero far' un decreto che chiuse la porta ad ogni remedio». El decreto que habían emitido los anteriores generales españoles era prohibir tratar de otros temas que no fuera la elección a General en las Congregaciones Generales. ARSI, Fondo Gesuitico 700, Miscellanea 1, f. 200r. 
la petición de nombrar un asistente francés, que revelaba el interés de estos jesuitas memorialistas por favorecer los intereses de las provincias francesas, lo que provocaría no pocas quejas de los jesuitas castellanos. Asimismo se pedía celebrar una congregación general que reformase, cuanto antes, éstos y otros defectos que se explicaban. Como éste, por los mismos años, llegaron al Santo Oficio otros memoriales anónimos, escritos igualmente por los jesuitas reformadores, con quejas parecidas, solicitando al tribunal romano un remedio cuanto antes. Se sabe que las quejas de estos memorialistas italianos eran discutidas en la Inquisición por un documento, fechado en enero de 1590 , en el que se exponía un catálogo de medidas o recomendaciones para mejorar el gobierno de la Compañía. Pero en ningún caso el General fue obligado a seguir las medidas, ni tampoco se proponían remedios sustanciales en el gobierno de la Orden, de manera que la Inquisición, aunque fortalecida por Sixto $V$, no satisfizo las demandas de los memorialistas italianos. Por otra parte, el fallecimiento de Sixto V, en 1590, disipó cualquier posibilidad real de que el pontífice pusiera remedio a los problemas propuestos por los memorialistas italianos a la Inquisición. Por si fuera poco, la inestabilidad pontificia dado que en dos años se sucedieron tres breves pontificados (Urbano VII, Gregorio XIV e Inocencio IX) dificultó aún más los objetivos de los memorialistas italianos. Cabe recordar que Gregorio XIV vino a confirmar el Instituto y sus privilegios, lo que acalló las ansias de reforma a la espera de la llegada de un pontífice que favoreciera sus intereses.

La elección de Clemente VIII, en enero de 1592, no resultó indiferente a los memorialistas italianos, parecía el momento idóneo para aplicar la reforma del instituto ignaciano. La espiritualidad oratoriana del pontífice, alejada de los ideales dominicos y franciscanos de otros papas, con un sentido más pastoral y su deseo de reformar las órdenes religiosas, dieron alas a un posible cambio, pero no de la estructura de la Compañía, sino de su espiritualidad. Resulta evidente el cambio en las peticiones de los memorialistas italianos durante el pontificado de Clemente VIII, centrándose en el proyecto de reformar espiritualmente a la Orden, dejando en un segundo plano todas aquellas reformas concernientes al gobierno de la Compañía, que tanto habían reclamado décadas antes con el P. Palmio. Desde los inicios de su pontificado, Clemente VIII se había mostrado partidario de reformar el espíritu y la disciplina de la Compañía, no así tanto el gobierno interno de la Orden. En abril de 1592, Aquaviva enviaba a todos los provinciales una larga instrucción con unas pautas de corrección que Clemente VIII quería introducir en la Orden. Señalaba el General que «desea Su Santidad que las cosas de las religiones se reduzcan á su primitivo espíritu, como tan seriamente nos lo encargó en la plática que hizo á los Generales de las Religiones». ${ }^{96}$ Bajo el título «de las cabezas y puntos que deseamos se remedien", y compuesta por un total de cuarenta epígrafes, la instrucción obligaba a que los

96 Archivo Histórico de la Provincia de Toledo de la Compañía de Jesús (AHPTSJ), Fondo Astrain. Subcarpeta 29a. Caja III Bis. Algunas advertencias y apuntamientos que se encargaron al P. Alonso Sánchez, para reparo y renovación del espíritu y disciplina religiosa. En Roma, 4 de Abril de 1592. Esta instrucción la llevó el P. Alonso Sánchez de Roma a las provincias españolas. jesuitas no se inmiscuyeran en cuestiones temporales, que se diera una mayor obediencia a los superiores, y en cuanto a las cuestiones espirituales, que se diera un mayor uso de la oración, de las penitencias y de los ayunos (incluyendo las mortificaciones exteriores).

La aparente predisposición de Clemente VIII a revisar la espiritualidad de la Compañía, unió los intereses de los memorialistas italianos en un proyecto común por acometer la «reforma universal» de la Compañía, que no era otra que imponer la espiritualidad del P. Gagliardi en toda la Orden. Para ello, solicitaban insistentemente al General y a la curia papal que se convocase una Congregación extraordinaria donde imponer los principios de la reforma.

En medio de este ardiente celo espiritual a través del cual se canalizaron todos los esfuerzos de los reformadores italianos, hubo intentos, por parte de influyentes cardenales, de reformar el gobierno de la Compañía por considerarlo distinto, en cierto modo privilegiado, con respecto al gobierno de otras órdenes religiosas. Este fue el caso del cardenal de Camerino, Mariano Pierbenedetti ${ }^{97}$, quien entregó a la Congregación del Santo Oficio un extenso memorial titulado Del governo della Compagnia di Gesù et sue imperfettioni en julio de $1592 .{ }^{98}$ Pero este documento había sido escrito en realidad en octubre de 1590, en el momento de mayor apogeo de los memoriales, no obstante había sido entregado a la Inquisición dos años más tarde. En este memorial se acusaba al General de dirigir una Orden que más bien parecía una Monarquía absoluta, y de nuevo el problema estaba en el origen hispano de la Compañía:

"(la nación italiana) come quella che per essere più vicina al capo, può, con maggior agevolezza, sapere i difetti di lui et del governo, et haver l'orecchio di Sommi pontefici con manco travaglio. Ove solamente l'italiani sono spesso governati et visitati da' forastieri, il che non hanno voluto né i spagnoli, né i tramontani. L'italiani soli sogliono haver lettori, predicatori et elettori d'altre nationi, gl'altri o non mai o di raro, massimamente i spagnoli; per non dir nulla della maggior licenza, che ad essi si concede, intorno al vivere, vestire, trattare et andare attorno ${ }^{99}$

Las soluciones que se daban en el memorial entregado por el cardenal de Camerino eran varias, muchas de ellas, expuestas ya por los memorialistas italianos: desde el nombramiento de un cardenal protector, pasando por visitadores apostólicos (preferentemente un prelado italiano), la visita del General a todas las provincias, etc. En el memorial se aseguraba que la única intención de este memorial era la de eliminar las peculiaridades del gobierno de la Compañía de carácter monárquico, igualándola en el gobierno al resto de órdenes religiosas. Aseguraba además que no había ninguna intención más allá que la de buscar el bien de la Iglesia y hacer de la Compañía una orden más eficaz a los planes evangelizadores del papado. La interpretación de este ataque del cardenal de Camerino al gobierno de Aquaviva debe enmarcarse dentro de los intentos de

97 Cardella 1793: 303-306.

98 ACDF, Santo Offizio, St. St. N3g. Varie relative a gesuiti, ff. 366r-382v. Del governo della Compagnia di Gesù et sue infettioni. La respuesta de la Compañía en ARSI, Fondo Gesuitico 700, Miscellanea I, ff. 215r-219v. Se hacen eco de este memorial tanto Catto 2009: 128-130, como Guerra 2001: 128-129.

99 ACDF, Santo Offizio, St. St. N3 g. 
reforma de Sixto $V$, al que Pierbenedetti se hallaba muy unido. Gregorio XIII nombró a Pierbenedetti obispo de Martirano en 1577, recibiendo la solemne consagración de manos del cardenal Felice Peretti (futuro Sixto V). Se dedicó al gobierno espiritual de su diócesis, buscando una mayor autonomía de los virreyes españoles, hasta que Sixto le reclamó en Roma para nombrarle Gobernador de Roma, trabajando en consonancia con la actuación que la Inquisición estaba llevando en la ciudad. Satisfecho con su labor en Roma, Sixto V le nombró cardenal. ${ }^{100}$ Alessandro Guerra en su estudio sobre el General Aquaviva lleva a afirmar que este cardenal tuvo gran veneración a Paulo V, por lo que se mostraba combativo a la hora de borrar de la Compañía todo remanente hispano. ${ }^{101} \mathrm{El}$ hecho de que el memorial, en diversos párrafos, coloque a la orden de los dominicos como un modelo ejemplar de gobierno que debía ser imitado por la Compañía, hace pensar que Camerino no estuviera vinculado con los memorialistas italianos, sino que trataba de limitar los privilegios de esta Orden por medio de la Inquisición romana. Por su parte, la Inquisición no iba a actuar ni en contra ni en favor del General, pues Clemente VIII ya proyectaba una Congregación extraordinaria para la Compañía donde debatir el devenir de la Orden. De nuevo, tras la Congregación extraordinaria, concretamente el 27 de enero de 1594 (once días después de la clausura de la congregación), el cardenal Pierbenedetti volvió a intentar atacar el gobierno de la Compañía, intentando intervenir en el nombramiento de los asistentes (a los que se debía ampliar los poderes, limitando así el poder del General), dado que no se había tenido en cuenta sus reformas en la Congregación. Fue frenado en este intento por el cardenal Francisco de Toledo, protector de los memorialistas italianos, que le forzó a que no se entrometiera en la actividad de la Compañía. Efectivamente, el pontificado de Clemente VIII se perfilaba muy distinto al de Sixto $\mathrm{V}$, y ni las reformas de los memorialistas italianos, ni los intereses inquisitoriales de ciertos cardenales, tuvieron éxito ante un pontífice que quiso contar con Aquaviva para reformar algunos aspectos de la Orden. Con todo, es preciso analizar la actuación de algunos de los jesuitas memorialistas durante la Congregación extraordinaria de la que fueron vetados por Aquaviva, pero que aprovecharon para inmiscuirse en cuestiones de estado y luchar por uno de sus mayores intereses: desestabilizar el dominio de la Monarquía hispana en Italia.

LOS MEMORIALISTAS ITALIANOS Y LA CONVERSIÓN DE ENRIQUE IV (1594)

Cuando se convocaba la $V$ Congregación general de la Compañía, la situación política en Europa era de máxima tensión. Enrique de Borbón había abjurado del calvinismo el 25 julio de $1593 .{ }^{102}$ Con este motivo, el duque de Nevers, don Luis Gonzaga, representante de Enrique, se marchaba a Roma con la misión de obtener la absolución del rey converso. Por su parte, desde la Monarquía hispana,

100 Cardella 1793: 303-306. En tiempos de Clemente VIII, fue un férreo defensor de la conciliación de Enrique IV. Fattori 2004: 36 n. 78, 77 n. 253.

101 Guerra 2001: 129

102 Wolfe 1993: 125-131. un anciano Felipe II ordenaba a sus embajadores que evitasen cualquier movimiento de la Santa Sede en favor del perdón del Borbón. No cabe duda que, al poco tiempo de que Ippolito Aldobrandini subiera al solio pontificio como Clemente VIII en 1592, su prioridad fue la de dar la absolución al monarca francés. Especialmente interesado en ello se mostraba su confesor, Felipe Neri, consciente del apoyo que se debía dar desde la curia papal al monarca francés para hacer frente a la hegemonía hispana (especialmente en los territorios italianos). Los prelados del grupo que apoyó la candidatura de Clemente VIII se mostraban igualmente favorables al perdón, y la elección de Aldobrandini no defraudó en este sentido. De esta manera, el ala oratoriana del colegio cardenalicio que se confesaba con Felipe Neri favoreció las negociaciones entre Clemente VIII y la diplomacia francesa. ${ }^{103}$ Cardenales tan influyentes como el oratoriano Cesar Baronio, Gianfrancesco Morosini, Alessandro Octaviano de' Medici -después León XI-104, Gabriele Paleotti, Agostino Valier, y Silvio Antoniano, que frecuentaban el oratorio de Neri y compartían unos mismos ideales políticos y religiosos, avivaron esta decisión del pontífice que sirvió para ir cambiando la fisionomía política europea. ${ }^{105}$ No es de extrañar, que el duque de Nevers al llegar a Roma, en noviembre de 1593, pidiera una audiencia con Felipe Neri para tratar este negocio francés. $Y$ esta decisión de Clemente VIII se traduciría, con los años, en el fortalecimiento de una Monarquía francesa, que unida por la fe católica, dejaba atrás su ruptura en confesiones y las guerras de religión, que tanto la habían debilitado durante la segunda mitad del siglo xVI. De la misma forma que la absolución de Enrique IV significó el cambio en el juego de poder de la corte papal, con el nombramiento de nuevos cardenales franceses o filofranceses, que sustentaran la política del monarca francés. ${ }^{106}$

En medio de este complejo panorama político, se convocaba la Congregación extraordinaria de la Compañía, bajo la presión de Felipe II y de Clemente VIII, con intereses contrapuestos. Pero además, Aquaviva no tuvo más remedio que reunirla ante la ruptura que se estaba produciendo en el seno de la Orden; por un lado, los memorialistas españoles apoyados por Felipe II y por los inquisidores castellanos, con la amenaza de separar la Orden en una rama española $-\mathrm{y}$ nombrar a un comisario nacional con cierta autonomía del general-si Aquaviva no favorecía los intereses hispanos; por el otro, los memorialistas italianos, unidos en ese momento por un mismo objetivo de reforma espiritual de la Compañía, apoyados por cardenales influyentes, entre otros, por un recién purpurado Francisco de Toledo, quien a su vez había influido en Clemente VIII para convocar una Congregación extraordinaria que diera solución a los problemas internos de la Orden. En medio de esta lucha de intereses se encontraba el general Aquaviva, quien buscó apoyo en numerosos príncipes católicos -especialmente mujeres de la realeza- para que apoyaran su gobierno y la unión de

103 Fattori 2004: 69-72; Barbiche 1965; Hinojosa 1896: 334-336 y Cistellini 1981.

104 Sanfilippo 2005 (visto el 2 de septiembre de 2015 http://www. treccani.it/enciclopedia/papa-leone-xi_\%28Dizionario-Biografico\%29/)

105 Frajese 1995: 59.

106 Visceglia 2010: 79-80. 
sus miembros. ${ }^{107}$ Lo que a continuación sucedió se podría resumir en una sutil maniobra del General, apoyada por Clemente VIII, al convocar sólo a los superiores que le eran fieles para que acudiesen a la congregación extraordinaria de noviembre de 1593. Evitó, por tanto, que acudiera ningún memorialista castellano ${ }^{108}$-convocando a superiores jesuitas de los reinos periféricos como Aragón y Andalucía, que no le daban ningún problema-, pero también evitó la participación de los memorialistas italianos. ${ }^{109} \mathrm{~A}$ pesar del abanico de problemas y frentes abiertos, especialmente el español y el italiano, que se le presentaba a Aquaviva al convocar esta Congregación, el resultado fue favorable al gobierno del General. Sin ninguna duda salió fortalecido, hasta el punto de imponer un decreto para castigar a los memorialistas y perturbadores de la unión de la Compañía. Por tanto, ni los memorialistas de una nación, ni de la otra, consiguieron sus intereses, pero si Aquaviva quería garantizarse un gobierno tranquilo, tuvo que ceder ante ciertas prerrogativas como por ejemplo la imposición de los decretos de limpieza de sangre para satisfacción de los inquisidores castellanos, o reunir una Congregación general cada seis años, o el relevo trienal de los asistentes generales. De la reforma espiritual de Gagliardi y los «zelatori» nada se resolvió.

Uno de los decretos por los que más luchó Aquaviva fue por la prohibición de que los jesuitas se entrometieran en cuestiones políticas, que el grupo de los «zelatori» no obedeció. A pesar de haber sido apartados de la Congregación, los jesuitas que rodeaban al P. Achille Gagliardi en Milán, mediaban para conseguir el perdón del monarca francés. El interés de estos jesuitas liderados por Gagliardi en este asunto temporal parece claro: ante la impopularidad de la Compañía en la Monarquía francesa, que iba a ser expulsada de París en $1594^{110}$, era necesario apoyar la conversión y absolución de Enrique IV para tratar de mejorar la situación de la Compañía en Francia. Igual que el papado comenzaba a negociar la absolución, estos

107 Era costumbre del general Aquaviva solicitar ayuda a los miembros de las familias reales que más apoyo daban a la Compañía. Con anterioridad, en 1588, ante la crisis de la visita inquisitorial a la Compañía en las provincias españolas, Aquaviva no dudó en pedir la protección de la emperatriz María y de su hijo el archiduque Alberto. En AHPTSJ, Fondo Astrain. Subcarpeta 2a. Lg. 37. Caja XVI-Bis. Carta no 60. Del P. Aquaviva a la Emperatriz, 15 de Octubre de 1588; ibídem, carta no 67. P. Aquaviva al cardenal Alberto, 27 de Diciembre de 1588.

108 Los jesuitas memorialistas castellanos se lamentaban al afirmar que Aquaviva "ha procurado que sus aliados de España (a los que les hizo él Superiores y dio officios honrosos) y no otros, vayan elegidos a esta Congregación General, y que estos procurasen (como lo han procurado en Castilla) que nadie ose dezir los daños que se an experimentado del mal gobierno del General». AHPTSJ, Fondo Astrain. Subcarpeta 12a. Caja I. Carta del P. Enrique Enríquez al Consejo de la Inquisición, Salamanca, 21 de Mayo de 1593.

109 El P. Achille Gagliardi no pudo asistir para reclamar la reforma espiritual que él, Berinzaga, y los jesuitas que le secundaban querían poner en marcha, dado que Aquaviva se lo impidió, pero le mantuvo distraído con el encargo de preparar dos tratados espirituales. Asimismo, para que estuviera tranquilo, Aquaviva le reconfirmó como prepósito de la Casa de S. Fedele, le hizo viceprovincial durante el tiempo que duró la Congregación y fue nombrado prefecto general de toda la provincia milanesa. Como él, los jesuitas de su grupo de reformadores eran favorecidos con cargos que debían atender, por lo que Aquaviva consiguió evitar la presencia de éstos en la Congregación. Pirri 1945: 27 y ss.

110 Descimon 2009: 86-104 jesuitas reformadores italianos la favorecieron, y atacaron la pasividad de un general Aquaviva que, por miedo a la reacción española, se mostraba ajeno a las cuestiones políticas en Francia. Las conexiones entre los jesuitas franceses que rodearon a Enrique IV y los jesuitas milaneses vinculados al P. Gagliardi resultaban evidentes. El propio Achille Gagliardi, cuando era rector en Milán había dado clase de filosofía a un joven Pierre Coton ${ }^{111}$, a quien puso en contacto con Borromeo y con la dama milanesa Isabella Berinzaga. Asimismo, Gagliardi influyó en su discípulo francés transmitiéndole su misticismo, que luego Coton continuó desarrollando en Francia, difundiendo incluso las obras de su maestro Gagliardi. Años más tarde, Pierre Coton, conseguiría ganarse la confianza de Enrique IV, quien enterado del apoyo de numerosos jesuitas -entre ellos, Gagliardi y el grupo de los zelatori- para conseguir la absolución apostólica, restituyó la Compañía en Francia en 1603. ${ }^{112}$ Pierre Coton acabó siendo nombrado predicador real e influyó en las decisiones políticas más importantes del Reino. ${ }^{113}$ El apoyo de Enrique IV a la Compañía fue tal, debido a la influencia del P. Coton, que a petición de este monarca, Aquaviva dio orden de crear la Asistencia jesuita en la Monarquía francesa a partir de 1608. No resulta extraño que la creación de la Asistencia francesa fuera una de las peticiones de reforma que aparecía en los memoriales de los jesuitas italianos enviados a la Inquisición romana, junto con el nombramiento de un asistente galo que favoreciera la expansión de la Compañía por el territorio francés, cuestión que no gustaba nada a los memorialistas castellanos, que querían mantener el gobierno en manos de jesuitas españoles. ${ }^{114}$

La mediación del P. Gagliardi en la absolución del monarca francés no fue una cuestión baladí. Desde noviembre de 1993 (coincidiendo con la apertura de la V Congregación) y durante los meses que siguieron a la reunión, Gagliardi fue a visitar en numerosas ocasiones a Giovambattista Padavino, representante de la República de Venecia en Milán. La intención del jesuita era conseguir la intercesión de Venecia, siendo uno de los estados italianos más potentes, para conseguir el perdón de Enrique de Borbón, siempre justificándose en que no era un «negotio de' principi, ma più tosto proprio di Sua Divina Maestà, per rispetto di conservar alla divotiene di Santa Chiesa quel nobilissimo regno» ${ }^{115}$. Para asegurarse de que Clemente VIII daría su perdón al monarca francés, Gagliardi proponía a Padavino que intercediera en la curia papal el cardenal veneciano Giovan Francesco Morosini. ${ }^{116}$ En los encuentros entre Gagliardi y Padavino, el jesuita se presentaba como fiel servidor de la Serenissima Republica, en tanto que él era de Padua, y justificaba la intervención de Venecia en la comprensión que debía tener esta República al malestar que provocaba el dominio español en Italia (que de igual manera lo comparaba con el mal gobierno de los superiores

\footnotetext{
111 Donnelly 2001: 983-984.

112 Nelson 2005.

113 Minois 1988: 326-349; Fragnito 2012: 350-357.

114 Cfr. Guerra 2001: 114.

115 Cfr. Cozzi 1963: 498.

116 Bonora 2012 (consultado on-line el 2 de septiembre de 2015 en http://www.treccani.it/enciclopedia/giovan-francesco-morosini_\%28 Dizionario-Biografico\%29/)
} 
españoles que estaban sufriendo los miembros italianos de la Compañía):

"Entrò poi a dirmi -escribía Padavino-che rincresceva sopramodo a lui et a tutti li suoi padri che occorresse cosi spesso, come si vedeva, che li principi italiani et oltramontai si valessero di loro nei negotii et maneggi di stato poichè si concitavano addosso molto odio senza alcun loro beneficio. Et che il Possevino in particolare saria stato malissimo trattato dalli francesi quando la prudenza del signor duca di Nevers non havesse rimediato all'inconveniente, ma che non possono ricusar di obedire a chi gli altri danni che ricevono questo è uno che la Serenità Vostra gli teneva per diffidenti et per dipendenti da' Spagnoli, ancorchè essi habbiano poca causa di esser tali, poichè in nessun luogo stanno peggio che nei stati di sua Maestà Catholica, trattandosi sopra tutto al presente di far un vicario genera in Spagna che saria con disunione et rovina grande della sua confraternità» ${ }^{117}$

Probablemente Aquaviva tuvo noticia de este episodio de mediación política de Gagliardi con el gobierno de Venecia en favor de Enrique IV $^{118}$, que le pudo costar el tener problemas con la Monarquía hispana. Tras el éxito de la Congregación, el General no dudó en castigar a los miembros más influyentes del grupo de los "zelatori», tratando de dispersarles a colegios más alejados, en unos casos, o quitándoles del gobierno de los colegios, en otros. De esta manera, el 14 de diciembre de 1594, el P. Gagliardi era sustituido en el gobierno de la casa profesa de Milán por el P. Giovanni Francesco Vipera y se le ordenaba abandonar Milán, consiguiendo alejarle de Isabella Berinzaga. ${ }^{119}$ El problema era que el gobernador de Milán, don Juan Fernández de Velasco, condestable de Castilla y León, y su mujer, la duquesa de Frías, se oponían rotundamente a la partida de Gagliardi ${ }^{120}$, porque ellos practicaban la espiritualidad mística del jesuita y de la dama milanesa. ${ }^{121}$ Velasco, con respecto a la política de la corte madrileña, mantenía contacto con el grupo de poder que favorecía los intereses de Clemente VIII, mostrándose obediente al pontífice, frente al partido castellano que se oponía a una intromisión de Roma en las decisiones políticas de la

117 Cozzi 1963: 491.

118 La República de Venecia resultó ser el primer estado italiano en reconocer a Enrique IV.

119 ARSI, Ital, 161, f. 214r. Gagliardi a Aquaviva, Milán 14 de diciembre de 1594. Posteriormente, en otra carta Aquaviva señalaba «e sarà bene tagliar una volta questo capo: perchè saria pericolosa cosa che, con questo trattar con Madonna Isabella delle cose nostre, un giorno non si facesse là alcun scisma» ARSI, Ital. 71, f. 86r. Aquaviva al P. Rosignoli, 20 de enero de 1595.

120 "Mi scrive il signor Presidente che tutto Milano ne mormora, che da molti si attribuisce tutto alla Compagnia, che questo è con infinita pena di tutti et massime de'buoni. Mi scrive il Contestabile una lettera lunga et di suo pugno, nella quale attesta coram Deo il mio ben portarmi, l'amor che più che mai mi porta, e la sodisfattione in tutto: lauda il mio partire, ma con Vostra Paternità mostra tal risentimento e tanto grave, ch'io non oso scriverlo ( ) II rimedio unico a me pare che sia il ritorno a Milano, con mostrar di esser stato qui per pochi giorni per il negotio del futuro collegio, e mi dà il cuore di placare iterum il Signor Contestabile, subito acquietar ogni rumore». ARSI, Ital. 161, f. 217v. También el Príncipe Giacomo Boncompagni, Duca di Sora en Milán, se opuso a la salida de Gagliardi, por lo que tuvo que escribirle Aquaviva para persuadirle. Gagaliardi a Aquaviva, Cremona, 29 diciembre 1594; Pirri 1945: 16-21.

121 Rurale 1998. monarquía hispana. ${ }^{122}$ Es por esto, por lo que Velasco, que protegía al P. Gagliardi, no veía mal que el jesuita interviniera en favor de la absolución de Enrique de Borbón, como tampoco se opusieron el resto de miembros del partido «papista» desde la corte madrileña. ${ }^{123}$

Finalmente Gagliardi tuvo que abandonar Milán, no sin antes escribir a Aquaviva recordándole que justo antes de celebrarse la Congregación extraordinaria fue visitado por uno de los «zelatori», presumiblemente el P. Maffei, para animarle a liderar el movimiento de estos jesuitas espirituales que debían actuar aprovechando la Congregación extraordinaria. El número de jesuitas a favor de la reforma espiritual de la Compañía -señalaba Gagliardi- ascendía "di cento et più» "124. Gagliardi esperaba que en la Congregación, Aquaviva tomase alguna decisión favorable al movimiento espiritual, pero no fue así, y la correspondencia posterior que Gagliardi envió a Aquaviva podría parecer de arrepentimiento y obediencia al general, pero la advertencia de este místico al General de que el número de jesuitas «zelatori» iba en aumento resultaba, en cierto modo, amenazante para la tranquilidad del gobierno de Aquaviva.

En la misma línea que Gagliardi, su amigo y reformador, el P. Antonio Possevino, en otoño de 1593, hizo también de mediador entre Enrique de Borbón y la Sede Apostólica. La iniciativa había partido de Clemente VIII, quien por consejo del cardenal Santori, había elegido a Possevino -buen diplomático y conocedor de la política francesa- para encontrarse con el duque de Nevers y explicarle los intereses de Clemente VIII. ${ }^{125}$ Seguidamente, Possevino escribía al papa explicándole las rectas intenciones del monarca francés, tratando de favorecer así el proceso. Los jesuitas castellanos, por su parte, se quejaban de que Possevino había sido fautor de un "herético relapso». ${ }^{126}$

Como estos dos jesuitas, es preciso resaltar el papel que jugó el P. Francisco de Toledo en la conciliación de Enrique IV aconsejando a Clemente VIII en todo el proceso de negociación. ${ }^{127}$ Este jesuita que gozó del favor de la familia Aldobrandini, y protegió a los jesuitas memorialistas italianos, formó parte de la Congregación para los asuntos con Francia, fundada tras el asesinato de Enrique III. Así, el nombramiento de cardenal del P. Toledo vendría determinado por la necesidad del papa de proveerse de fieles colaboradores que favoreciesen las relaciones con la monarquía francesa. En este sentido, el diplomático francés, el cardenal Arnaud d'Ossat, aseguraba que la absolución del monarca francés fue debida, en gran parte, a las gestiones del cardenal Toledo. ${ }^{128}$

122 Martínez Millán 2003.

123 Sobre el partido papista y su relación con la Compañía en Jiménez Pablo 2014: 214-228.

124 Pirri 1945: 15-22.

125 Las negociaciones en Dorigny 1759: 365 y ss.; y en Paruta 1887: 38-39, 99-101.

126 Cozzi 1963: 490.

127 Sobre su actividad diplomática en este y otros asuntos anteriores: Cozzi 1960: 80.

128 Visceglia 2010: 42; Fattori 2004: 42. 
ROBERTO BELLARMINO S.I. EN LA INQUISICIÓN ROMANA: EL SILENCIO DE LOS MEMORIALISTAS ITALIANOS

La participación del P. Roberto Bellarmino ${ }^{129}$ en el Santo Oficio romano sirvió para disipar cualquier miedo del general Aquaviva a una intervención inquisitorial en el gobierno de la Orden, como había sucedido en el pasado con la Inquisición española. Bellarmino también participó en otro dicasterio romano, siendo el primer jesuita que llegó a ser consultor de la Congregación del Índice en 1587. Le siguió el P. Francisco de Toledo, quien no fue admitido en el Índice hasta el 4 de febrero de 1588. Toledo era conocido en la curia papal desde tiempos de Pío V (1566-1572), mientras que la presencia de Bellarmino en los negocios curiales se hizo más firme con posterioridad, durante el pontificado de Sixto V (1585-1590). La participación de manera oficial de estos dos jesuitas en la Congregación del Santo Oficio, ya como cardenales, fue lógicamente posterior a la Congregación extraordinaria de 1594, cuando Aquaviva abolió la prohibición de que los jesuitas pudieran aceptar cargos inquisitoriales. La entrada de la Compañía en la Inquisición -tanto en la española, como en la italiana y la portuguesa- fue reclamada por el monarca español en dicha asamblea, pero también deseada por Clemente VIII, quien tenía cerca de sí a destacados teólogos jesuitas -como Toledo y Bellarmino- de los que se podía valer para el funcionamiento del órgano inquisitorial. Esta restricción de ocupar cargos inquisitoriales se había impuesto en la Compañía debido a los problemas que se podían derivar del apoyo de algunos jesuitas a los intereses políticos y religiosos de Felipe II y de sus ministros castellanos. No obstante, en el caso italiano, no era tan evidente, la Inquisición era un brazo del pontificado, un instrumento de control ideológico, no tan vinculado a los intereses políticos, como en el caso español, al menos en apariencia, aunque en la práctica también sirvió para que el papado pudiera influir, más eficazmente, sobre la jurisdicción eclesiástica y la ideología religiosa de los

129 Sobrino del papa Marcello II. Estudió filosofía en el colegio Romano (1561-1563). Asimismo estudió teología en Padua (1567-1569) y Lovaina (1569-1570). En los Países Bajos, donde la amenaza calvinista era continua, fue profesor en la facultad de Teología de Lovaina (15701576), desarrollando su pensamiento tomista y su método controver sista. En 1576 ocupó la cátedra de controversias en el Colegio Romano que le llevó a escribir sus Controversiae. En la década de los 90 del siglo XVI presidió la comisión sobre la Ratio Studiorum, empeñándose en extenderla en todos los colegios jesuitas. Entre sus cargos como superior de la Compañía fue rector del Colegio Romano entre 1592 y 1594 y después provincial de Nápoles. En 1596, Clemente VIII le reclamó en Roma como teólogo apostólico a la muerte de Francisco de Toledo, y le nombró consultor del Santo Oficio. En esta decisión de tener cerca de sí a Bellarmino influyó el cardenal Baronio, gran amigo y protector de Bellarmino, quien quiso el cardenalato para su amigo. Su catecismo, Dottrina cristiana, se publicó en 1598, gozando de gran aceptación. El 3 de marzo de 1599 fue nombrado cardenal, pero su intervención en la controversia de Auxiliis a favor de Luis de Molina provocó su marcha de Roma, en 1602, para gobernar el arzobispado de Capua. Desde su sede, trabajó como pastor, visitando las parroquias y predicando. En 1605, Paulo $\mathrm{V}$ le reclamó en Roma, incluyéndole en diversas congregaciones, incluidas el Santo Oficio y la del Índice. Su intervención en el Santo Oficio se centró en los procesos contra los filósofos y científicos italianos Bruno, Campanella y Galileo. Destacó su intervención a favor de Paulo $\checkmark$ en el interdetto de Venecia y en contra del regalismo de Jacobo I de Inglaterra. Para reconstruir esta breve biografía de Bellarmino: Galeota 1966 y 1997; Blackwell 1991; Godman 2000; Motta 2005. estados italianos. En la Monarquía hispana, por tanto, contar con jesuitas en la Inquisición podía ser un arma de doble filo, en el caso de que acabaran favoreciendo los intereses del monarca hispano ${ }^{130}$, pero en Roma, la presencia de Bellarmino en la Inquisición favorecía, sin ninguna duda, a los intereses de Aquaviva, y con ello, a los de Clemente VIII. De manera que, tras la Congregación extraordinaria llegó el nombramiento cardenalicio del P. Toledo en 1596 y, tras su muerte, en 1599, el de Bellarmino. El cardenalato les abrió las puertas a estos dos jesuitas con un nombramiento oficial como cardenales de la Congregación inquisitorial, a la vez que siguieron siendo censores de la del Índice. ${ }^{131}$

La confianza del P. Aquaviva en Bellarmino se había traducido en el nombramiento de este último como rector del colegio romano de 1592-1594, en los años más polémicos durante la Congregación extraordinaria, y luego, como provincial de Nápoles en 1594-1597. El General contó con él para preparar el texto definitivo de la Ratio, eligiendo a Bellarmino, en primer lugar, para la comisión que estudiaría los precedentes proyectos. Tanto en Roma como en Nápoles, aplicó con éxito la Ratio Studiorum. ${ }^{132}$ El nuevo método académico -conocido como modus italicus- había sido elaborado desde la curia jesuítica, así como aprobado por el papado. La aplicación de la Ratio fue un cambio trascendental en los colegios jesuitas, pues significaba la sustitución del método que se venía aplicando desde los primeros jesuitas, que no era otro que el método de estudio aprendido por Ignacio de Loyola en Alcalá y París. ${ }^{133}$ Pero este método de aprendizaje estaba mal visto por los jesuitas reformadores liderados por el P. Palmio que lo tacharon de riguroso y, despectivamente, le llamaban el modo "español», por lo que la aceptación de la Ratio, para este grupo de reformadores italianos, era un cambio necesario. La Compañía con Aquaviva y Bellarmino conoce una readaptación a los intereses de Clemente VIII, en el que mucho tuvo que ver todos los acontecimientos políticos del momento, entre ellos, el fallecimiento de Felipe II y la subida al trono de un Felipe III más sumiso a Roma. ${ }^{134}$ Aquaviva había apoyado a Bellarmino frente a la amenaza de Sixto V de meter en el índice el primer tomo de sus Controvesiae. ${ }^{135}$ $Y$ es que con su doctrina política, Bellarmino ratificó al pontífice como la máxima autoridad espiritual, defendiendo su hegemonía ideológica, pero lo que Sixto $\mathrm{V}$ no aceptaba era que Belarmino limitase la autoridad papal a un poder indirecto sobre aquellos estados que no le pertenecían. ${ }^{136}$

Tanto la Congregación Inquisitorial como la del Índice mantenían un control ideológico sobre la sociedad. La definición de la ortodoxia pasaba por el examen de estas dos congregaciones, por lo tanto, el análisis de la ideología y espiritualidad de los cardenales que las componían revela los intereses en la actuación de ambos organismos. Cuando Bellarmino comenzó como consultor de la Congregación

130 En una carta fechada en diciembre de 1583 Aquaviva afirmaba su malestar porque la Compañía ejerciera cargos inquisitoriales. Citada por Prosperi 1996: 576.

131 Col 2006: 518-519.

132 Galeota 2000: 384-385.

133 Galeota 2000: 387, n. 12 y Codina Mir 1968: 337-348.

134 Sobre todos los cambios que se produjeron en la Compañía durante el reinado de su hijo Felipe III en Jiménez Pablo 2014: 213-315.

135 Le Bachelet 1907: 227-246 y Motta 2005: 434-435.

136 Godman 2000: 100 y ss. 
del Índice, bajo el pontificado de Sixto V, el monopolio de dicha institución estaba en manos de cardenales vinculados al oratorio de Felipe Neri, tales como Bordini ${ }^{137}$, Paleotti, Borromeo, Antoniano, Valier ${ }^{138}$, y el consultor Marcantonio Maffa. ${ }^{139}$ Sixto $V$ no estuvo vinculado al carismático reformador Filippo Neri como otros pontífices ${ }^{140}$, pero contó con cardenales del ala oratoria para la Congregación del Índice, incluyendo pronto, en 1587, a Bellarmino, reputado teólogo jesuita, que aunque nunca fue hijo espiritual de Neri, su fuerte amistad con Baronio le llevó a apreciar siempre la congregación del Oratorio. ${ }^{141}$

Con estos cardenales espirituales se entró en una fase nueva en el Índice, menos intransigente, en la que la expurgación de libros se convirtió en una práctica común. ${ }^{142}$ Lo que se tradujo en que la Congregación del Índice pasaba de ser un mero instrumento de control doctrinal, severo y rígido, a un laboratorio de definición de la identidad religiosa, con una actuación más flexible. En este proyecto, Bellarmino destacó dando soluciones prácticas, censuras practicables que daban mayor flexibilidad a la relación censura-doctrina. Aplicaba, por tanto, el método controversista en sus censuras, emitiendo unos juicios perfectamente justificados, midiendo el grado de heterodoxia que reflejaban los libros incautados, lo que daba menos rigidez a las censuras. Ahora bien, el problema para Bellarmino, y para la Compañía en el caso de tener algún problema doctrinal en sus libros, era que el gobierno de Sixto $V$ se apoyó en la Congregación del Santo Oficio, no en la del Índice, donde contó con la dirección del todopoderoso inquisidor y cardenal Giulio Antonio Santori. ${ }^{143}$

Santori había conseguido con Sixto $\mathrm{V}$ colocar a la Inquisición por encima del resto de Congregaciones, con una extensa red de influencia entre inquisidores, obispos y nuncios fieles al Santo Oficio, que le otorgaban un poder nunca antes conocido. En este sentido, Santori se quejaba de la división de la censura entre la Congregación del Santo Oficio y la del Índice, consiguiendo reforzar su influencia sobre la del Índice, que en numerosas ocasiones quedaba neutralizada en su actuación por el Santo Oficio. Esta falta de delimitación entre las dos Congregaciones jugó siempre en favor de la inquisitorial. El monopolio de Santori sobre la Inquisición le permitió controlar el instrumento más poderoso del papado, que le hizo mantener un gran protagonismo en la curia, aunque nunca fue elegido pontífice, a pesar de que su nombre salió como posible candidato en diversos cónclaves. Fue, sin duda, el rival más fuerte en el cónclave de 1592 en el que salió elegido Clemente VIII. ${ }^{144}$

\footnotetext{
137 Bonadonna Russo 1992: 347.

138 Bragagnolo 2009: 169.

139 Godman 2000: 77
}

140 Aunque el método asistencial que implantó Neri en Roma, y la devoción que el oratoriano estaba creando en la sociedad romana, conectaba con los objetivos piadosos que Sixto $\mathrm{V}$ tenía para Roma. Resulta evidente la influencia de la práctica de las Sette Chiese, impuesta por Neri en Roma, en los planes urbanísticos del papa Peretti que quiso favorecer esta devoción. Bonadonna Russo 1992: 341.

141 Los volúmenes de Cistellini están llenos de citas en los que se confirma la amistad y el apoyo que se tuvieron Bellarmino y Baronio. Cistellini 1989.

142 Motta 2010

143 Fue cardenal inquisidor desde 1570 y prefecto de la Congregación desde 1586 hasta su muerte en 1602.

144 Borromeo 1978.
Y precisamente fue durante el pontificado de Clemente VIII que Santori llegó a bloquear la promulgación del nuevo índice de 1593, en el que el pontífice había trabajado fervientemente con Bellarmino, Marcantonio y Ascanio Colonna, que venía a corregir el antiguo índice de tiempos de Sixto V, realizado en marzo de $1590 .{ }^{145}$

Parece claro, por tanto, que Sixto $V$ dejó a los cardenales espirituales (oratorianos) el dominio del Índice, consciente de que la Congregación del Santo Oficio dominaba sobre la actuación de éstos, y es que Sixto $V$ conectaba con la intransigencia religiosa de Santori, siguiendo ambos la línea marcada por el férreo Paulo IV, y después continuada por Pío $\mathrm{V}$, frente a una mayor suavidad de los cardenales oratorianos a la hora de actuar por medio del Índice.

Esta rivalidad entre los cardenales espirituales del Índice, por un lado, y el dominio de Santori sobre la Inquisición romana, con su intransigencia religiosa, por el otro, al igual que tuvo su reflejo en las promulgaciones de los Índices, también afectó a los problemas de censura de las obras de la Compañía. Bellarmino trataba por todos los medios de controlar él mismo la censura jesuítica y que no llegara a manos de Santori. De nuevo, el caso de Gagliardi y Berinzaga puso de manifiesto estas contradicciones. En 1601, Bellarmino actuaba como examinador de las obras de Gagliardi ${ }^{146}$ y la dama milanesa. Fallecido ya el P. Toledo, quien en su momento había dado por buena las obras de Gagliardi, era el turno de Bellarmino. En ese año, Gagliardi y Berinzaga se encontraban en Roma, lejos de haber aparcado sus ideales de reforma espiritual, Gagliardi volvía a la curia romana. Pero Aquaviva se había adelantado, previniendo a Clemente VIII y a Bellarmino de las intenciones de Gagliardi, que finalmente, fueron frenadas. Efectivamente, el momento era otro, y la mística de Gagliardi ya no tenía cabida en la espiritualidad de la Compañía. Era el momento de una Compañía confirmada por el propio pontífice en la Congregación extraordinaria, que parecía irse adaptando a los intereses evangelizadores de Clemente VIII -conocida como la conquista espiritual de la Compañía en sus misiones-, y Bellarmino contribuía como teólogo que justificaba este fin. Para evitar disturbios en Roma, Clemente VIII ordenó revisar las obras espirituales de Gagliardi, encomendándoselas a Bellarmino. En apoyo a Aquaviva, Bellarmino vio errores graves y peligrosos en las obras de Gagliardi. Con esto se cerraba definitivamente el caso Gagliardi-Berinzaga, no sin antes explicar Bellarmino que el hecho de examinar las obras místicas del jesuita había sido una decisión del papa, y que todo se había llevado en secreto, para que no interviniera la Inquisición, dirigida por Santori, donde el problema se podría haber complicado y extendido a toda la Orden. ${ }^{147}$

En el momento de la elección de Clemente VIII, en 1592, la Congregación del Santo Oficio estaba compuesta por Santori, Deza, Pinelli, Bernerio, Boccafuoco y Sfondrato,

145 Ricci 2002 y 2010.

146 Cuando estaba en la Compañía ya actuó como censor en la revisión en 1579 del comentario evangélico de Alfonso Salmerón, en examinar las proposiciones de la Concordia liberi arbitrii de Luis de Molina en 1588, y los Commentarii alla Tertia pars de la Summa Theologiae de Francisco Suárez en 1590.

147 La actuación de Bellarmino en el caso de Gagliardi en Pirri 1945: 48-57. 
entrando a formar parte de ella, durante su pontificado, los cardenales Toledo y Bellarmino, menos rigurosos y más acordes al modo de actuar de los cardenales espirituales. ${ }^{148}$ Ciertamente, el cardenalato de Bellarmino, que fue solicitado insistentemente por su gran amigo el cardenal Baronio $^{149}$, le fue conferido en 1599 , lo que le permitió la entrada como miembro oficial en la Congregación del Santo Oficio (dos años antes había sido nombrado consultor, pero no como titular). Todos estos cambios fueron posibles por la intercesión de Clemente VIII en la orden ignaciana para que los jesuitas pudieran tener cargos inquisitoriales.

Cuando ya desde el papado, con ayuda de la Inquisición, en los territorios italianos se había homogeneizado la fe, erradicado la herejía, extirpado las desviaciones populares, y controlado la filosofía, ciencia y literatura (los casos de Galileo, Campanella y Bruno fueron claros ejemplos de ello), Roma pudo lanzarse a la conquista espiritual del mundo, cuya justificación debe mucho a la doctrina de Bellarmino, y al pragmatismo de Clemente VIII al dar origen a la Congregación de Propaganda Fide. Y en esta expansión católica los jesuitas contribuyeron de manera eficaz, con una Compañía más compacta, y desde luego más romana y menos hispana, sin fuertes divisiones internas marcadas por intereses políticos.

\section{BiBLIOgRAFÍA}

Aicardo, J. M. 1922. Comentario a las constituciones de la Compañía de Jesús, III. Madrid: Blass, S. A. Tipográfica.

Anselmi, G. M. 1981. "Per un'archeologia della Ratio», en G. P. Brizzi (eds.), La «Ratio Studiorum»: Modelli culturali e pratiche educative dei Gesuiti in Italia tra Cinque e Seicento: 11-42. Roma: Bulzoni.

Astrain, A. 1909. Historia de la Compañía de Jesús. Madrid: Razón y Fe, III.

Barbiche, B. 1965. "L'influence française à la cour pontificale sous le règne de Henri IV». Mélanges d'archéologie et d'histoire. 77/1: 277-299.

Barbieri, F. 1911. "La riforma dell'eloquenza sacra in Lombardia ispirata da S. Carlos». Archivio Storico Lombardo. 38: 231-262.

Bascapè, C. 1931. I barnabiti e la controriforma in Lombardia. Milán: Liber.

Berra, L. 1923. "Nuove notizie dell' Academia delle Notti Vaticane». Giornale storico della letteratura italiana. 81: 342-374.

Bethencourt, G. 1997. La Inquisición en la época moderna. España, Portugal, Italia, siglos XV-XIX. Madrid: Akal.

Blackwell, R. J. 1991. Galileo, Bellarmine and the Bible. Notre Dame: University of Notre Dame Press.

Bonadonna Russo, M. T. 1992. "Sisto V e gli Oratoriani», en M. Fagiolo y M. L. Maddona, Sisto V. (I. Roma e il Lazio): 339-356. Roma: Istituto poligrafico e zecca dello stato.

Bonora, E. 2012. Morosini, Giovan Francesco. Dizionario Biografico degli Italiani. 77: 129-130. Roma: Treccani.

Borromeo, A. 1978. «España y el problema de la elección papal de 1592». Cuadernos de Investigación Histórica. 2: 174-200.

Borromeo, A. 1998. «Archbishop Carlo Borromeo and the ecclesiastical policy of Philip II in the State of Milan», en J. M. Headly y J. B. Tomaro, San Carlos Borromeo. Catholic Reform and ecclesiastical politics in the second half of the Sixteenth Century: 85-111. London \& Toronto: Associated University Presses.

Borromeo, A. 2003. "La Congregazione cardinalizia dell'Inquisizione», en Romeo, G. (ed.), L'Inquisizione. Atti del Simposio internazionale 29-31 ottobre 1998: 323-344. Città del Vaticano: BAV.

148 Simoncelli 1976: 130.

149 Cistellini 1989: 1299, n. 423.
Bragagnolo, M. 2009. Giovanni Cipriani, La mente di un inquisitore. Agostino Valier e l'Opusculum De cautione adhibenda in edendis libris (1589-1604). Firenze: Nicomp.

Busolini, D. 2001. "V. Giustiniani», en Dizionario Biografico degli Italiani. 57. Roma: Treccani.

Cardella, L. 1793. Memorie storiche de' cardinali della Santa Romana Chiesa. Roma: Stamperia Paglierini, V.

Castellani, G. 1934. "La fondazione del collegio di Brera di Milano secondo i documenti inediti del tempo (1563-1572)». La Civiltà Cattolica. 85/II: 509-522.

Castellani, G. 1945. "La vocazione alla Compagnia di Gesù del P. Antonio Possevino da una relazione inedita del medesimo». Archivum Historicum Societatis lesu. 14: 102-124.

Catalano, G. 1954-1955. "Controversie giurisdizionali tra Chiesa e Stato nell'età di Gregorio XIII e Filippo II». Atti dell'Accademia di scienze, lettere e belle arti di Palermo, s. 4, XV/2: 5-306.

Cattaneo, E. 1992. "La cultura di San Carlo. San Carlo e la cultura» en N. Raponi y A. Turchini, Stampa, libri e letture a Milano nell'età di Carlo Borromeo: 5-37. Milán: Vita e Pensiero.

Catto, M. 2009. La Compagnia divisa. Il dissenso nell'ordine gesuitico tra'500 e '600. Brescia: Morcelliana.

Cistellini, A. 1981. "ll cardinale Federico Borromeo, San Filippo e la Vallicella», en Atti dell'Accademia di San Carlo. Inaugurazione del IV anno accademico: 91-133. Milán: Biblioteca Ambrosiana.

Cistellini, A. 1988. San Filippo Neri, l'Oratorio e la Congregazione oratoriana. Storia e spiritualità. Brescia: Morcelliana, I-III.

Cistellini, A. 1989. San Filippo Neri. L'oratorio e la Congregazione Oratoriana. Brescia: Morcelliana, I.

Clement, M. 1998. "Mystiques et théologiens (1579-1640)», en Les Fruits de la dissention religieuse, fin Xve-début XVIII ${ }^{e}$ siècles: 181192. Publications de I'Université de Saint-Étienne: Institut Claude Longeon.

Codina Mir, G. 1968. Aux sources de la pédagogie des jésuites. Le modus parisiensis. Roma: IHSJ.

Col, A del.; Paolin G. (ed.) 1991. L'Inquisizione romana in Italia nell'età moderna. Archivi, problemi di metodo e nuove ricerche, Atti del seminario internazionale, Trieste, 18-20 maggio 1988. Roma: Ministero per i beni culturali e ambientali, Ufficio centrale per i beni archivistici.

Col, A. del. 2003. "Strutture e attività dell'Inquisizione romana», en Romeo, G. (ed.), L'Inquisizione. Atti del Simposio internazionale 29-31 ottobre 1998: 345-380. Città del Vaticano: BAV.

Col, A. del. 2006. L'Inquisizione in Italia. Dal XII al XXI secolo. Milán: Mondadori.

Costa, F. 1986. "Il carteggio Peretti-Borromeo per l'edizione romana delle opere di sant'Ambrogio, 1579-1585». Miscellanea Francescana. 86: 1015-1071.

Cozzi, G. 1960. «Un documento sulla crisi della Sacra Lega: Le confidenze del padre Francisco Toledo all'avogadore di comun Nicolò Barbarigo (ottobre 1572)». Archivio Veneto s. V. 67: 76-96.

Cozzi, G. 1963. «Gesuiti e politica sul finire del '500. Una mediazione di pace tra Enrico IV, Filippo II e la Sede Apostolica proposta del P. Achille Gagliardi alla Repubblica di Venezia». Rivista Storica Italiana. 75: 477-537.

Dagens, J. 1931. "La source du Bref discours de l'abnégation intérieure». Revue d'Histoire Ecclésiastique. 27/2: 318-349.

Dagens, J. 1952. Bérulle et les origines de la restuaration catholique (1575-1611). París: Desclée de Brouwer.

Delumeau, J. 1961. «Les progrès de la centralisation dans l'État pontifical au XVI ${ }^{\mathrm{e}}$ siècle». Revue Historique. 85: 399-410.

Descimon, R. 2009. «Chastel's Attempted Regicide (27 december 1594) and its subsequent transformation into an 'affair», en A. Forrestal y E. Nelson (eds.), Politics and Religion in Early Bourbon France: 86-104. Basingstoke: Palgrave Macmillan.

Donnelly, J. P. 2001. Coton, Pierre, en C. O'Neill y J. M. Dominguez (eds.), DHSI: 983-984. Roma-Madrid, IHSJ, II.

Dorigny, G. 1759. Vita del P. Antonio Possevino. Verona.

Dossi, L. 1963. «Da quattro secoli i Gesuiti a Milano». Diocesi di Milano. 4: 308-315. 
Fattori, M. T. 2004. Clemente VIII e il sacro collegio (1592-1605): Meccanismi istituzionali e accentramento di governo. Stuttgart: Anton Hiersemanu.

Fernández Collado, A. 1991. Gregorio XIII y Felipe II en la nunciatura de Felipe Sega (1577-1581). Aspectos político, jurisdiccional y de reforma: 245-264. Toledo: Estudio Teológico de San Ildefonso.

Firpo, M. 1981. «Il provesso inquisitoriale di cardinal Giovanni Morone. Edizione critica», vol. I. II compendium. Roma: Istituto Storico Italiano per l'Età Moderna e Contemporanea.

Firpo, M. 1983. «Filippo II, Paolo IV e il processo inquisitoriale del cardinal Giovanni Morone». Rivista Storica Italiana 95: 5-62.

Firpo M. y Marcatto, D. 1981. «Il primo processo inquisitoriale contro il cardinal Giovanni Morone (1552-1553)». Rivista Storica Italiana. 93: 71-142.

Fois, M. 1995. «ll Collegio Romano: I'istituzione, la struttura, il primo secolo di vita». Roma moderna e contemporanea 3/3: 571-599.

Fragnito, G. 1997. La Bibbia al rogo: La censura ecclesiastica e i volgarizzamenti della Scrittura (1471-1605). Bolonia: Il Mulino.

Fragnito, G. 2012. "Tra parroci confessori e gesuiti: Il governo della coscienza di Enrico IV di Borbone», en J. Martínez Millán, M. Rivero Rodríguez, G. Versteegen (coords.), La Corte en Europa: Política y Religión (siglos XVI-XVIII): 333-358. Madrid: Polifemo.

Frajese, V. 1995. "Tendenze dell'ambiente oratoriano durante il pontificato di Clemente VIII. Prime considerazioni e linee di ricerca». Roma moderna e contemporanea. 3/1: 57-80.

Galeota, G. 1966. Bellarmino contro Baio a Lovanio. Roma: Herder.

Galeota, G. 1997. «La teologia controversista», en G. Occhipinti, Storia della teologia da Pietro Abelardo a Roberto Bellarmino: 523-565. Roma-Bolonia: EDB, II.

Galeota, G. 2000. «Claudio Acquaviva e Roberto Bellarmino: due protagonisti della riforma cattolica», en F. lappelli y U. Parente, Alle origini dell'Università dell'Aquila. Cultura, università, colleg gesuitici all'Inizio dell'età moderna in Italia meridionale: 381-397. Roma: IHSJ.

García-Villoslada, R. 1941. Manual de historia de la Compañía de Jesús, 1540-1940. Madrid: Aldecoa.

García-Villoslada, R. 1954. Storia del Collegio Romano dal suo inizio (1551) alla soppressione della Compagnia di Gesù (1773). Roma: Universitatis Gregorianae.

Giannini, M. C. 1998. «El martillo sobre el ánima: Filippo II e la bolla In Coena Domini nell'Italia spagnola tra religione e sovranità (1568 1570)», en el Congreso Internacional Felipe II (1598-1998), Europa dividida, la monarquía católica de Felipe II (Universidad Autónoma de Madrid, 20-23 abril 1998): 251-270. Madrid: Parteluz, III.

Gilmont, J. F. 1961. Les écrits spirituels des premiers jésuites: 291-294. Roma: IHSI.

Giordano, S. 2000. Enciclopedia dei Papi: 202-222. Roma: Istituto della Enciclopedia italiana, III.

Godman, P. 2000. The Saint as Censor. Robert Bellarmine between Inquisition and Index. Leiden-Boston-Köln: Brill.

Guerra, A. 2001. Un general fra le milizie del Papa. La vita di Claudio Aquaviva scritta da Francesco Sacchini della Compagnia di Gesù. Milán: FrancoAngeli.

Guerra, A. 2002. "Os meum aperui et attraxi spiritum quia mandata tua desiderabam. Claudio Acquaviva nella direzione spirituale della Compagnia di Gesù», en M. Catto, I Gagliardi, R. M. Parrinello (eds.) Direzione spirituale tra ortodossia ed eresia. Dalle sculo filosofiche antiche al Novecento: 219-245. Brescia: Morcelliana.

Guibert, J. de. 1953. La spiritualité de la Compagnie de Jésus. Roma: IHSJ.

Hinojosa, R. de. 1896. Los despachos de la diplomacia pontificia en España. Madrid, I.

Incisa della Rocchetta, G. y Vian, N. 1957. II primo processo per San Filippo Neri nel Codice Vaticano latino 3798 e in altri esemplari dell'archivio dell'oratorio di Roma. Ciudad del Vaticano, I.

Iparraguirre, I. 1946. Historia de la práctica de los Ejercicios espirituales de San Ignacio de Loyola I. Bilbao-Roma: Mensajero.

Iparraguirre, I. 1964. Estilo espiritual jesuítico (1540-1600). Bilbao: El Mensajero.
Jiménez Pablo, E. 2010. «El influjo de Roma en la organización y dirección de la Compañía de Jesús (1573-1581)», en J. Martínez Millán y M. Rivero Rodríguez (coords.), Centros de poder italianos en la monarquía hispánica (siglos XV-XVIII): 1261-1310. Madrid: Polifemo, II.

Jiménez Pablo, E. 2014. La forja de una identidad. La Compañía de Jesús (1540-1640). Madrid, Polifemo.

Le Bachelet, X. M. 1907. «Bellarmin à I'Index. Documents nouveaux». Études. 44: 227-246.

Luca, G. de. 1931. "Quelques manuscrits romains sur Gagliardi» (Notices et extraits). Revue d'Ascétique et de Mystique 12: 142-152.

Malena, A. 2003. L'eresia dei perfetti. Inquisizione romana ed esperienze mistiche nel Seicento italiano. Roma: Ed. di Storia e Letteratura.

Marcocchi, M. 1995. "Modelli professionali e itinerari di perfezione nella trattatistica sugli stati di vita», en P. Pissavino y G. Signorotto, Lombardia borromaica, Lombardia Spagnola 1554-1659: 845-893. Roma: Bulzoni, II.

Marcora, C. 1969. «S. Carlo ed il gesuita Benedetto Palmio». Memorie Storiche della Diocesi di Milano. 16: 7-53.

Martínez Millán, J. 1998. "Transformación y crisis de la Compañía de Jesús (1578-1594)», en F. Rurale (dir.), I Religiosi a Corte. Teologia, política e diplomacia in Antico Regime: 101-129. Roma: Bulzoni.

Martínez Millán, J. 2003. "La crisis del "partido castellano" y la transformación de la Monarquía Hispana en el cambio de reinado de Felipe II a Felipe III». Cuadernos de Historia Moderna. 2: 11-38.

Maryks, R. A. 2010. The Jesuit Order as a Synagogue of Jews. Jesuits of Jewish ancestry and Purity-of-Blood Laws in the Early Society of Jesus. Leiden-Boston: Brill.

Michelini, V. 1983. I barnabiti. Chierici Regolari di San Paolo alle radici della Congregazione 1533-1983. Milán: NED.

Minois, G. 1988. Le Confesseur du Roi: Les directeurs de conscience sous la monarchie française. París: Fayard.

Motta, F. 2005. Bellarmino. Una teologia politica della Controriforma. Brescia: Morcelliana.

Motta, F. 2010. "Roberto Bellarmino, santo», en A. Prosperi (ed.), Dizionario storico dell'Inquisizione: 1334-1335. Pisa: Edizioni della Normale, III.

Nelson, E. 2005. The Jesuits and the Monarchy: Catholic Reform and Political Authority in France (1590-1615): 57-96. Aldershot: Ashgate.

O’Neill, Ch. E. y Domínguez J. M. (dirs.), 2001. Diccionario histórico de la Compañía de Jesús (DHCJ). Roma-Madrid, Universidad Pontificia de Comillas, I-III.

Oreste, G. 1960. «Adorno, Francesco». Dizionario Biografico degli Italiani. 1: 293-295. Roma: Treccani.

Parente, U. 1992. «Nicolò Bobadilla e gli esordi della Compagnia di Gesù in Calabria», en V. Sibilio, I gesuiti e la Calabria: 19-56. Reggio Calabria: Laruffa Editore.

Parisciani, G. 1991. «Fra Felice Peretti OFMConv (Sisto V) nei registri di introito ed esito di Montalto, 1565-1580». Miscellanea Francescana. 91: 455-500.

Paruta, P. 1887. La legazione di Roma (1592-1592). Venecia, II.

Paschini, P. 1926. "Due episodi della Contro-Riforma in Italia». Archivio della R. Società romana di storia patria. 49: 314-320.

Pastor L. 1927. Historia de los Papas XIV. Barcelona: Gustavo Gili.

Pavone, S. 2004. I gesuiti dalle origini alla soppressione (1540-1773). Bari: Laterza.

Pellegrini, C. 1909. "San Carlo ed i gesuiti». San Carlo Borromeo nel terzo centenario della canonizzazione MDCX-MCM 10: 164-166.

Pellegrini, C. 1983. «ll programma educativo del Collegio Gallio di Como dalla fondazione al 1629», en I/ cardinale Tolomeo Gallio e il suo Collegio (1582-1983): 135-150. Como.

Penone, D. 1998. I dominicani nei secoli. Panorama storico del ordine dei Frati Predicatori. Bolonia: ESD.

Petrocchi, M. 1948. Il quietismo italiano del Seicento. Roma: Edizioni di storia e letteratura.

Petrocchi, M. 1954. "Per la storia della spiritualità del Cinquecento. Interpretazioni della "Dama Milanese" e del gesuita Gagliardi». Archivio Storico Italiano. 112: 252-264. 
Pirri, P. 1945. «Il P. Achille Gagliardi, la dama milanese, la riforma dello spirito e il movimiento degli zelatori». AHSI 14: 1-72

Pirri, P. 1947. «Gli annali gregoriani di Gian Pietro Maffei. Premesse storiche per una revisione critica». Archivum Historicum Societatis lesu. 16: 56-97.

Pirri, P. 1951. "ll Breve compendio di Achille Gagliardi al vaglio di teologi gesuiti». Archivum Historicum Societatis lesu. 20: 238.

Ponnelle, L. y Bordet, L. 1986. San Filippo Neri e la società romana del suo tempo (1515-1595) (traducción de T. Casini y prefacio de G. Papini). Florencia: Libreria Editrice Florentina.

Prosperi, A. 1991. "Per la storia dell'Inquisizione romana», en Col, A del., Paolin G. (eds.), L'Inquisizione Romana in Italianell'Età Moderna.Archivi, problemi dimetodoenuovericerche: 27-64. Roma: Ministero per i beni culturali e ambientali.

Prosperi, A. 1996. Tribunali della coscienza. Inquisitori, confessori, missionari. Turín: Einaudi.

Quondam, A. 2004. "Il metronomo classicista», en M. Hinz, R. Righi y D. Zardin (eds.), I gesuiti e la Ratio studiorum: 379-507. Roma: Bulzoni, 2004.

Ricci, S. 2002. II Sommo Inquisitore. Giulio Antonio Santori tra autobiografia e storia (1532-1602). Roma, Salerno.

Ricci, S. 2010. «Santoro, Giulio Antonio» en Dizionario storico dell'Inquisizione: 1370-1376. Pisa: Edizioni della Normale, III.

Romeo, G. 2002. L'Inquisizione nell'Italia moderna. Bari: Laterza.

Rurale, F. 1992. I gesuiti a Milano. Religione e Politica nel secondo Cinquecento. Roma: Bulzoni.

Rurale, F. 1995. "I Gesuiti e l'autorità episcopale tra cinque e seicento», en P. Pissavino y G. Signorotto, Lombardia Borromaica, Lombardia spagnola 1554-1659: 895-913. Roma: Bulzoni, II.

Rurale, F. 1997. "Carlo Borromeo, Botero, Mazzarino: incontri e scontri nella ridefinizione del potere sacerdotale e della politica moderna» en F. Buzzi y D. Zardin (ed.), Carlo Borromeo e l'opera della "grande reforma». Cultura, religione e arti del governo nella Milano del pieno Cinquecento: 289-302. Milán: Cinisello Balsamo.

Rurale, F. 1998. "Clemente VIII, i gesuiti e la controversia giurisdizionale milanese», en G. Signorotto y M. A. Visceglia (eds.), La corte di Roma tra Cinque e Seicento "Teatro» della politica europea: 323366. Roma: Bulzoni.

Rurale, F. 2006. "La Compagnia di Gesù tra riforme, controriforme e riconferma dell'Istituto (1540-inizio XVII secolo)», en M. C. Giannini, Religione, Conflittualità e cultura. II clero regolare nell'Europa d'antico regime: 25-52. Roma: Bulzoni.

Sanfilippo, M. 2005. «Leone XI, papa», en Dizionario Biografico degli Italian 64. Roma: Treccani.

Santos Hernández, A. 1998. Jesuitas y obispados. La Compañía de Jesús y las dignidades eclesiásticas. Madrid: Universidad Pontificia Comillas.
Scaduto, M. 1968. Catalogo dei gesuiti d'Italia (1540-1565). Roma: IHSJ.

Scaduto, M. 1972. «ll governo di S. Francesco Borgia (1565-1572)». Archivum Historicum Societatis lesu. 41: 136-175.

Scaduto, M. 1974. Storia della Compagnia di Gesù in Italia. L'epoca di Giacomo Lainez 1556-1565. L'azione. Roma: La civiltà cattolica, IV.

Scaduto, M. 1984. "Pio V, Alfonso II d'Este e il Borgia». Archivum Historicum Societatis lesu. 53: 31-54.

Serrano, L. 1942. "Un legado pontificio en la corte de Felipe II». Hispania. 2: 64-91.

Signorotto, G. 1991. "Gesuiti, carismatici e beate nella Milano del primo Seicento» en G. Zarri (ed.), Finzione e santità tra medioevo ed età moderna: 177-201. Turín: Rosenberg \& Sellier.

Simoncelli, P. 1976. "Clemente VIII e alcuni provvedimenti del Sant'Uffizio. "De italis habitantibus in partibus haereticorum". Critica Storica. 13: 129-172.

Sommervogel, C. 1890. Bibliothèque de la Compagnie de Jesús: 54-55. Bruxelles, I.

Soto Artuñedo, W. 1999. «La Ratio studiorum: la pedagogía de la compañía de Jesús». Proyección. 46: 259-276.

Tacchi Venturi, G. 1951. Storia della Compagnia di Gesù in Italia. Roma: Società Editrice Dante Alighieri, II.

Tacchi Venturi, P. 1910. Storia della Compagnia di Gesù in Italia. RomaMilán: Società Editrice Dante Alighieri, I.

Tacchi Venturi, P. 1938. "L'anno santo del 1575 celebrato da San Carlo in Milano, secondo una lettera inedita del P. Benedetto Palmio». Echi di San Carlo Borromeo. 13: 3-5.

Törne, P.O. von. 1907. Ptolémée Gallio, cardinal de Côme. Étude sur la cour de Rome, sur la secrétairerie pontificale et sur la politique des papes au XVI siècle. París.

Viller, M. 1931. "L’Abrégé de la Perfection de la Dame Milanaise». Reveu d'ascétique et mystique. 12: 50.

Visceglia, M. A. 2010. Guerra, Diplomacia y Etiqueta en la Corte de los Papas (siglos XVI-XVII). Madrid: Polifemo.

Visceglia, M. A. 2010. Roma papale e Spagna. Diplomatici, nobili e religiosi tra due corti. Roma: Bulzoni.

Wicki, J. 1959. «Rodolfo Pio da Carpi erster und einzinger Kardinal protektor der Geselleschaft Jesu». Miscellanea Historiae Pintificiae XXI, Saggi storici intorno al papato: 243-267. Roma: Pontificia Università Gregoriana.

Wolfe, M. 1993. The conversion of Henri IV. Politcs, power and religious belief in Early Modern France. Cambridge: University of Cambridge.

Zanardi, M. 1998. «La Ratio atque institutio studiorum Societatis lesu: tappe e vicende della sua progresiva formazione (1541-1616)». Annali di storia dell'educazione e delle istituzioni scolastiche. 5: 135-164. 